\author{
RESEARCH ARTICLE \\ 10.1029/2019JC015418 \\ Key Points: \\ - Ice speed $\left(0.75 \mathrm{~m} \mathrm{~s}^{-1}\right)$ measured \\ during intense polar cyclones is \\ the fastest recorded in the Southern \\ Ocean \\ - Mean ice drift follows the wind, but \\ with a strong inertial component, \\ period $\approx 13 \mathrm{hr}$ \\ - Pancake ice drift agrees with \\ the free drift approximation \\ (no internal ice stresses), \\ even though remotely sensed \\ concentration is $100 \%$
}

Correspondence to: A. Alberello,

alberto.alberello@outlook.com

Citation:

Alberello, A., Bennetts, L., Heil, P., Eayrs, C., Vichi, M., MacHutchon, K., et al. (2020). Drift of pancake ice floes in the winter Antarctic marginal ice zone during polar cyclones. Journal of Geophysical Research: Oceans, 125, e2019JC015418. https://doi.org/10. 1029/2019JC015418

Received 25 JUN 2019 Accepted 2 MAR 2020

Accepted article online 12 MAR 2020

(C)2020. American Geophysical Union. All Rights Reserved.

\section{Drift of Pancake Ice Floes in the Winter Antarctic Marginal Ice Zone During Polar Cyclones}

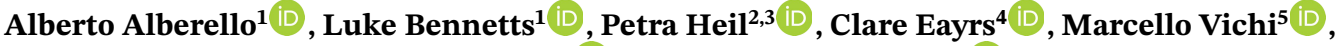 \\ Keith MacHutchon $^{6}$, Miguel Onorato ${ }^{7,8}$ (D) and Alessandro Toffoli ${ }^{9}$ (D) \\ ${ }^{1}$ School of Mathematical Sciences, University of Adelaide, Adelaide, South Australia, Australia, ${ }^{2}$ Australian Antarctic \\ Division, Hobart, Australia, ${ }^{3}$ ACE-CRC, Hobart, Australia, ${ }^{4}$ Center for Global Sea Level Change, New York University \\ Abu Dhabi, Abu Dhabi, United Arab Emirates, ${ }^{5}$ Department of Oceanography \& Marine Research Institute,University \\ of Cape Town, Rondenbosch, South Africa, ${ }^{6}$ Department of Civil Engineering, University of Cape Town, Rondenbosch, \\ South Africa, ${ }^{7}$ Dipartimento di Fisica, Università di Torino, Torino, Italy, ${ }^{8}$ INFN, Torino, Italy, ${ }^{9}$ Department of \\ Infrastructure Engineering, The University of Melbourne, Parkville, Victoria, Australia
}

Abstract High temporal resolution in situ measurements of pancake ice drift are presented, from a pair of buoys deployed on floes in the Antarctic marginal ice zone during the winter sea ice expansion, over 9 days in which the region was impacted by four polar cyclones. Concomitant measurements of wave-in-ice activity from the buoys are used to infer that the ice remained unconsolidated, and pancake ice conditions were maintained over at least the first 7 days. Analysis of the data shows (i) the fastest reported ice drift speeds in the Southern Ocean; (ii) high correlation of drift velocities with the surface wind velocities, indicating absence of internal ice stresses $>100 \mathrm{~km}$ from the ice edge where remotely sensed ice concentration is $100 \%$; and (iii) presence of a strong inertial signature with a $13 \mathrm{hr}$ period. A Lagrangian free drift model is developed, including a term for geostrophic currents that reproduce the $13 \mathrm{hr}$ period signature in the ice motion. The calibrated model provides accurate predictions of the ice drift for up to 2 days, and the calibrated parameters provide estimates of wind and ocean drag for pancake floes under storm conditions.

Plain Language Summary During the Antarctic winter, small pancake ice floes, which form rapidly in wavy conditions, dominate new ice growth and create a dynamic environment. However, there are only a handful of local observations of pancake ice drift, particularly during the intense polar cyclones that frequently reshape the ice cover. More observations are needed to generate better understanding and modeling of pancake ice response to winds, waves, and currents. We describe a set of pancake ice drift and wave-in-ice measurements over 9 days in which four polar cyclones affected the region, from buoys deployed on pancake floes $100 \mathrm{~km}$ from the ice edge. We also develop an ice drift model.The data show how the cyclones affect ice drift and contain the fastest reported ice speed in the Southern Ocean $\left(0.75 \mathrm{~m} \mathrm{~s}^{-1}\right)$.

The instantaneous drift speed closely correlates with the wind speed, and the ice also displays a $13 \mathrm{hr}$ period rotational motion that we reproduce in the model with forcing from ocean currents. We show that pancake ice is in free drift, despite sea ice covering the entire ocean surface in the measurement region and that the model predicts drift accurately over 2 days with calibration of only two parameters.

\section{Introduction}

Sea ice modulates energy, mass, and momentum exchanges between the ocean and atmosphere, thereby playing a pivotal role in the global climate system (McPhee et al., 1987; Notz, 2012; Vihma et al., 2014). During the winter sea ice advance around Antarctica, pancake ice floes-small, roughly circular floes that form in the presence of ocean surface waves_-dominate new ice growth (Wadhams et al., 2018). Dynamics and thermodynamics of pancake floes control the evolution of the Antarctic marginal ice zone (MIZ) (Doble et al., 2003; Doble \& Wadhams, 2006; Roach, Horvat, et al., 2018) and also the emerging Arctic MIZ (Pedersen \& Coon, 2004; Roach, Smith, et al., 2018; Smith et al., 2018; Wadhams et al., 2018). The MIZ is the outer ice belt of the sea ice region, where atmosphere-ocean-sea ice interactions are most intense (Strong et al., 2017; Wadhams, 1986). Contemporary numerical models struggle to predict the spatial variability of advance and 
retreat of sea ice around Antarctica (Hobbs et al., 2015, 2016; Kwok et al., 2017; Roach, Dean, et al., 2018), resulting in strong biases in ocean-atmosphere heat fluxes and salt input to the ocean (Doble, 2009).

It has been argued that, except for a few sectors around Antarctica, trends in sea ice duration and extent are dominated by storms rather than large atmospheric modes (Kwok et al., 2017; Matear et al., 2015; Schroeter et al., 2017). Vichi et al. (2019) have shown that intense winter polar cyclones continuously reshape the edge of the Antarctic MIZ by advecting warm air on the sea ice and forcing ice drift. This generates strong coupling between thermodynamics and dynamics (Stevens \& Heil, 2011). Strong coupling also exists in the Arctic, where storms have been shown to reverse the winter sea ice advance by melting (Smith et al., 2018) and advecting (Lund et al., 2018; Smith et al., 2018) newly formed pancakes. Moreover, intense storm events cause rapid ice drift that enhances mixing and deepens the surface mixed layer, thus promoting heat exchanges with the water sublayers (Ackley et al., 2015; Castellani et al., 2018; Zippel \& Thomson, 2016). Knowledge of the dynamical response of pancake ice floes to the frequent and intense storm events that impact the winter Antarctic MIZ is required to model the evolution of the MIZ and improve climate predictions (Barthélemy et al., 2018), particularly now that prognostic floe size information is being included in models (Bennetts et al., 2017; Roach, Horvat, et al., 2018).

For over a century, atmospheric drag has been identified as the main driver of ice drift (Nansen, 1902; Shackleton, 1920); a rule of thumb indicates that the wind factor (the ice to wind speed ratio) is $2 \%$ (Leppäranta, 2011; Thorndike \& Colony, 1982). In the Arctic MIZ, Wilkinson and Wadhams (2003) calculated an average wind factor of $2.7 \%$ for pancake ice and noted a correlation with the ice concentration $\left(i_{c}\right)$, with a larger wind factor of 3.9\% toward the ice edge where $i_{c}<25 \%$ and a smaller value of $2.2 \%$ toward the interior of the MIZ where $i_{c}>75 \%$. For the Antarctic, Doble and Wadhams (2006) calculated a wind factor of 3-3.5\% in pancake ice conditions. Doble and Wadhams (2006) used a far shorter sampling rate of $0.33 \mathrm{hr}$ than the $24 \mathrm{hr}$ rate used by Wilkinson and Wadhams (2003), possibly resulting in the larger wind factor (see section 5). More recently, in the Arctic and for a low ice concentration $\left(i_{c}=33 \%\right.$ ), Lund et al. (2018) reported wind factors up to 5\% for pancake ice but defined for wind at $17 \mathrm{~m}$ height rather than the standard $10 \mathrm{~m}$ height. They showed low correlation with the wind forcing and suggested that currents (not measured) contribute significantly to sea ice drift. The wind factors calculated by Wilkinson and Wadhams (2003), Doble and Wadhams (2006), Lund et al. (2018), and others do not separate out the effect of currents and Coriolis - they assume that wind is the only forcing — but usually include a turning angle to account for the Coriolis forcing. As a result, wind stresses are likely to be underestimated (Leppäranta, 2011). The Nansen number, that is, the ratio between ice drift and wind speed for an ocean at rest, explicitly indicates the role of wind stresses only (Leppäranta, 2011), but to the best of our knowledge, the Nansen number has not previously been reported for pancake ice.

In sophisticated contemporary models, sea ice drift is governed by a general horizontal momentum equation in which wind stresses act together with other external stresses (ocean drag, Coriolis forcing, waves, and ocean tilt as external forcing) and with a rheology term used to model internal stresses (Heil \& Hibler, 2002; Leppäranta, 2011). Granular rheologies have been developed for the MIZ (Feltham, 2005; Shen et al., 1987), in which internal stresses are generated by floe-floe collisions, and the magnitude of the internal stresses depends on concentration of the floes and their granular "temperature" (a measure of the turbulent kinetic energy of the floes). However, in low ice concentration internal stresses are small, and the rheology term is typically neglected (Hunke et al., 2010; Herman, 2012). Modeled wind-induced stresses are defined by a standard drag formulation (Martinson \& Wamser, 1990), that is, proportional to air-sea ice drag coefficient and the relative velocity between wind and ice. Similarly, ocean-induced stresses are defined by a water-sea ice drag coefficient and the ocean currents, seldom available in ice-covered regions (Nakayama et al., 2012). Scarcity of in situ observations (conducted for different seasons, regions, and ice types) and heterogeneity of ice conditions, particularly in the highly dynamical MIZ (Doble, 2009), have led to a wide range of sea ice drag coefficients (Leppäranta, 2011), undermining predictive capabilities.

We report and analyze a new set of pancake ice drift measurements during the winter expansion of the Antarctic MIZ and during intense storm conditions that reshaped the edge of the MIZ at synoptic scales (Vichi et al., 2019). We then develop a Lagrangian free drift model, based on the general sea ice horizontal momentum equation, and quantify the reciprocal effect of winds and currents on pancake ice drift by providing the Nansen number and the derived current. 

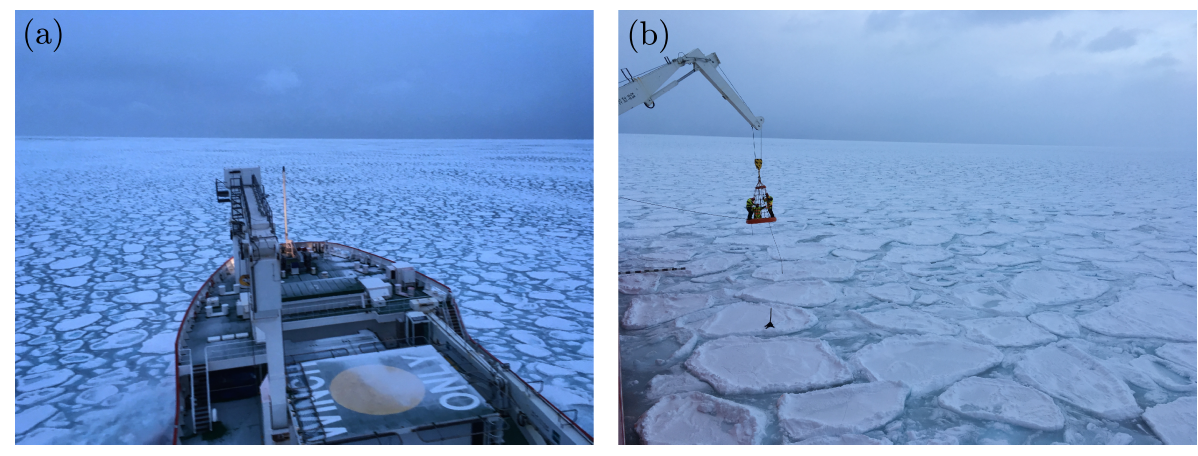

Figure 1. (a) Ice conditions on 4 July 2017 and (b) deployment of the buoys on pancake floes using the ship crane.

\section{Field Experiment and Prevailing Conditions}

The instruments were deployed during a winter voyage to the Antarctic MIZ by the icebreaker SA Agulhas II (Figure 1a). The voyage departed from Cape Town, South Africa, on 28 June 2017 along the WOCE I06 transect and reached the MIZ on 4 July 2017 at $62.5^{\circ} \mathrm{S}$ and $30^{\circ} \mathrm{E}$, at which time a polar cyclone was crossing the ice edge.

At midday on 4 July 2017, a pair of waves-in-ice observation systems (Kohout et al., 2015), hereafter simply referred to as buoys, were deployed on separate pancake ice floes $(\approx 3 \mathrm{~m}$ in diameter; Figure $1 \mathrm{~b})$ at $62.8^{\circ} \mathrm{S}$ and $29.8^{\circ} \mathrm{E}$ in $\approx 5,000 \mathrm{~m}$ deep water (Arndt et al., 2013); they were $\approx 100 \mathrm{~km}$ from the ice edge and $\approx 1 \mathrm{~km}$ apart. The buoys are expendable devices that record position and wave spectral characteristics but do not have onboard meteorological stations. One of the buoys, B1, recorded data continuously at a sampling rate of $15 \mathrm{~min}$ for 8 days and $18 \mathrm{hr}$, from 12:00 on 4 July until 06:00 on 13 July 2017, until signal was lost (most likely due to the battery running out). The other buoy, B2, recorded at $15 \mathrm{~min}$ for the first 6 days from deployment; after which, to save battery life, the sampling rate was reduced to $2 \mathrm{hr}$, which allowed it to record data for 3 weeks in total. In this study, we only consider the period over the 9 days in which both buoys were operational to allow analysis of the buoys' relative motion and ice internal stresses. The relative precision of a buoy's location with respect to the previous position is about $1 \mathrm{~m}$, meaning that error in the derived velocity is $\pm 0.001 \mathrm{~m} \mathrm{~s}^{-1}$; this is small compared to measured velocities ( $\approx 0.3 \%$ of the mean velocity).

Sustained winds over the open ocean, up to $33 \mathrm{~m} \mathrm{~s}^{-1}$ according to the ship meteorological station, generated large waves in the open ocean, with the significant wave height $\left(H_{S}\right)$ up to $14 \mathrm{~m}$ and peak period $\approx 12 \mathrm{~s}$ according to the ERA5 reanalysis data (Copernicus Climate Change Service (C3S), 2017), and propagating toward the ice edge. The buoys indicated that the wavefield maintained $\approx 50 \%$ energy after $100 \mathrm{~km}$ of propagation into the MIZ, that is, ice-induced dissipation is $\approx 50 \%$. Sea ice concentration was $i_{c}=100 \%$, as sourced from AMSR2 (Beitsch et al., 2014), with a resolution of $3.125 \mathrm{~km}$ (sourced from https://seaice. uni-bremen.de/), and confirmed by ASPeCt observations (de Jong et al., 2018) that span a $1 \mathrm{~km}$ radius and are averaged over $10 \mathrm{~min}$ while the ship advances in ice. We note that accuracy of ASPeCt observations relies on the training level of the observer, so that errors are difficult to quantify (Beitsch et al., 2015); at the same time, remote sensing ice concentration retrievals struggle at the ice edge due to smearing and atmospheric corrections (Andersen et al., 2006). Deck observations (see Figure 1), supported by objective automatic camera measurements, revealed that on 4 July 2017 the MIZ was an unconsolidated mixture of pancake ice floes covering $\approx 60 \%$ of the surface and of characteristic diameter $3.2 \mathrm{~m}$ (Alberello, Onorato, Bennetts, et al., 2019) and interstitial frazil ice $(\approx 40 \%)$. In situ observations in the MIZ lasted $\approx 24 \mathrm{hr}$, after which the ship headed back to Cape Town.

Environmental conditions were retrieved from satellite data and reanalysis products over the $\sim 9$ days that both buoys returned data. AMSR2 and ERA5 reanalysis (Copernicus Climate Change Service (C3S), 2017) were used to retrieve ice concentration and surface wind velocities (at $10 \mathrm{~m}$ height) respectively. ERA5 wind fields are provided at $0.25^{\circ}$ spatial resolution and hourly frequency. ERA5 also provides wave properties, but these are only available where the ice concentration is below 30\% (Doble \& Bidlot, 2013); implementation of improved waves-in-ice physics in operational models is ongoing (Squire, 2020). In the manuscript, we refer to ERA5 wave conditions in open water $\left(i_{c}=0 \%\right)$ to avoid bias due to inaccurate waves-in-ice modeling at the ice edge. 

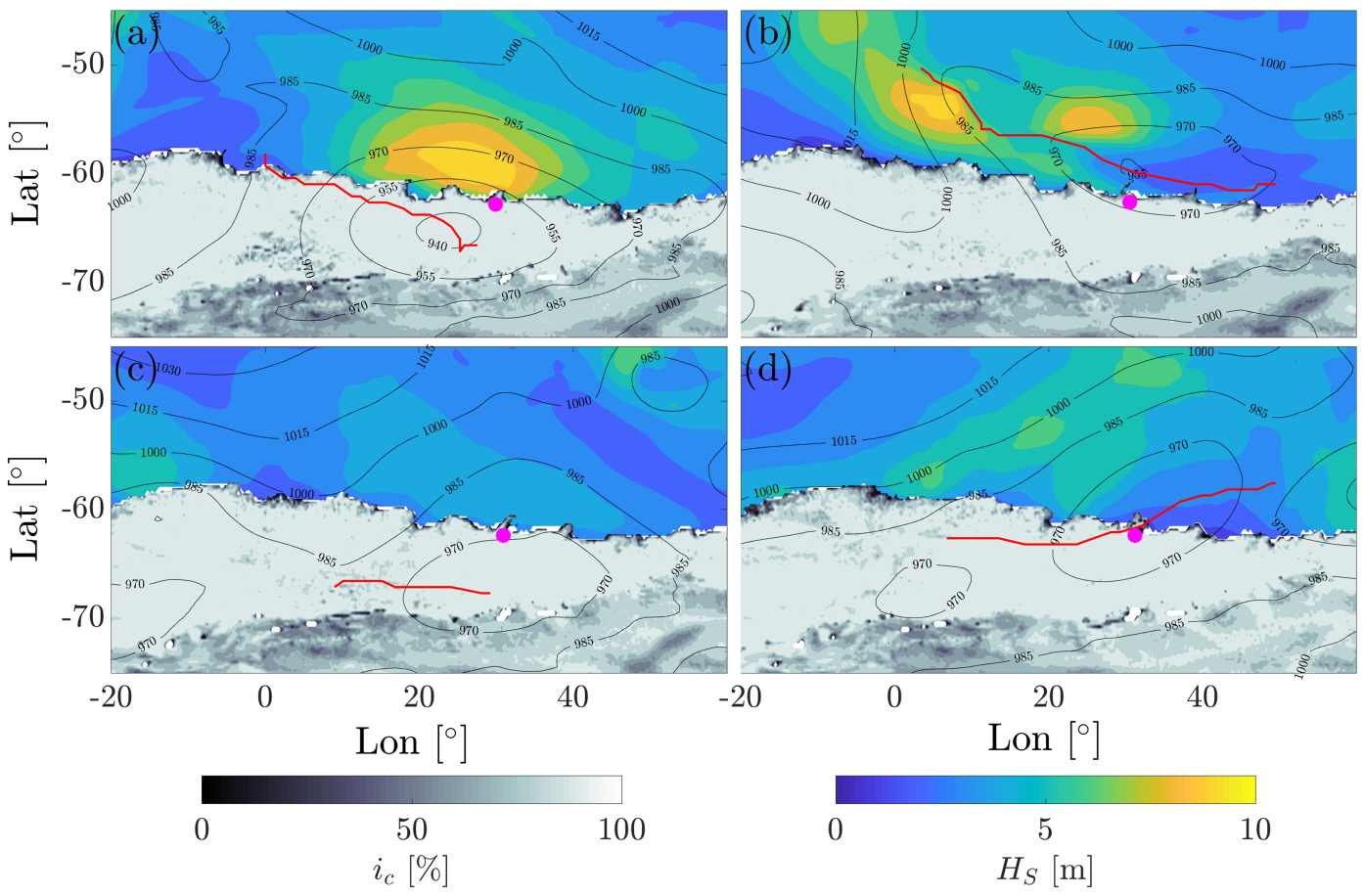

Figure 2. Environmental conditions when the polar cyclones were close to the buoys: (a) at 15:00 on 4 July, (b) at 18:00 on 7 July, (c) at 21:00 on 10 July, and (d) at 15:00 on 12 July. The cyclone tracks are shown in red and the buoy B1 with the magenta circle. The shadings show the AMSR2 ice concentration and the ERA5 significant wave height. The contour lines (in black) denote the ERA5 isobars in $\mathrm{hPa}$.

ERA5 reanalysis shows that another three cyclones, albeit less intense, impacted the MIZ surrounding the buoys over the 9 days. Figures $2 a-2 d$ show the tracks of the four polar cyclones overlaid on the significant wave height (in open water) and the ice concentration. The cyclogenesis of the first and most intense polar cyclone took place over open water and its cyclolysis (decay) over the MIZ southeast of the buoys (see track in Figure 2a). The second polar cyclone skirted the ice edge, traveling over open water to the north of the buoys (Figure 2b). The other two experienced cyclogenesis over the MIZ. The third cyclone (Figure 2c) was short lived, and its cyclolysis was south of the buoys in the MIZ. The last cyclone transited to the northwest of the buoys before progressing over open water (Figure 2d). All observed polar cyclones strongly affected the evolution of the edge of the MIZ at synoptic scales (Vichi et al., 2019). The asymmetric cyclonic structure transports moist warm air over the sea ice, while the opposite side drags ice toward the open ocean. Concurrently, strong winds associated with polar cyclones generated large waves (larger during the first two polar cyclones that developed over open water) that impacted the edge of the MIZ.

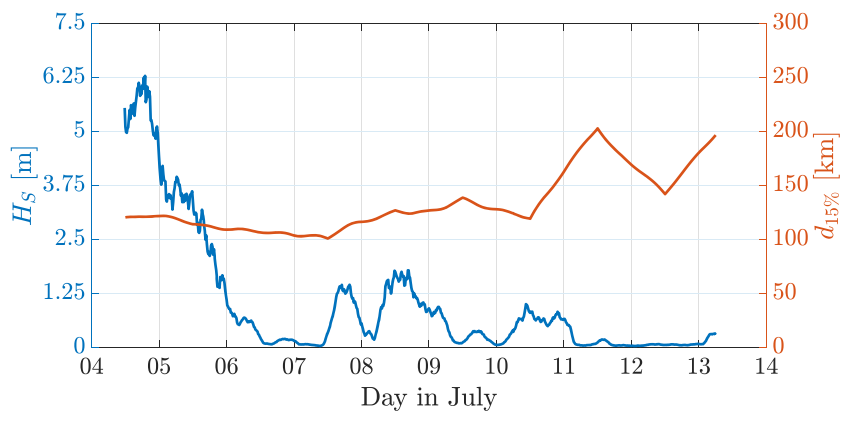

Figure 3. Significant wave height from Buoy B1 (left axis; blue), distance between Buoy B1 and the ice edge defined by 15\% concentration (right axis; orange).
Wave-in-ice intensity (represented by $H_{S}$ ) measured by Buoy B1 is shown in Figure 3; the peak period was $15-20$ s. Peaks in wave-in-ice activity are associated with the transit of cyclones, and they show high correlation with the open water wave height (Vichi et al., 2019). Intense wave-in-ice activity after deployment suggests that the MIZ was composed of pancake floes, at least until 11 July 2017, when waves ceased. Figure 3 also shows the distance between Buoy B1 and the ice edge, which is defined as the daily mean position of the AMSR2 15\% ice concentration in the sector $29-33^{\circ} \mathrm{E}$ and denoted $d_{15 \%}$. The buoys are $100-200 \mathrm{~km}$ from the estimated ice edge, although sector averaging smears ice edge features and so the distance must be interpreted with care.

\section{Drift Measurements and Analysis}

\subsection{Buoy Drift}

The track of Buoy B1 from deployment superimposed on the AMSR2 ice concentration is shown in Figure 4, where each subplot is 2 days apart. 

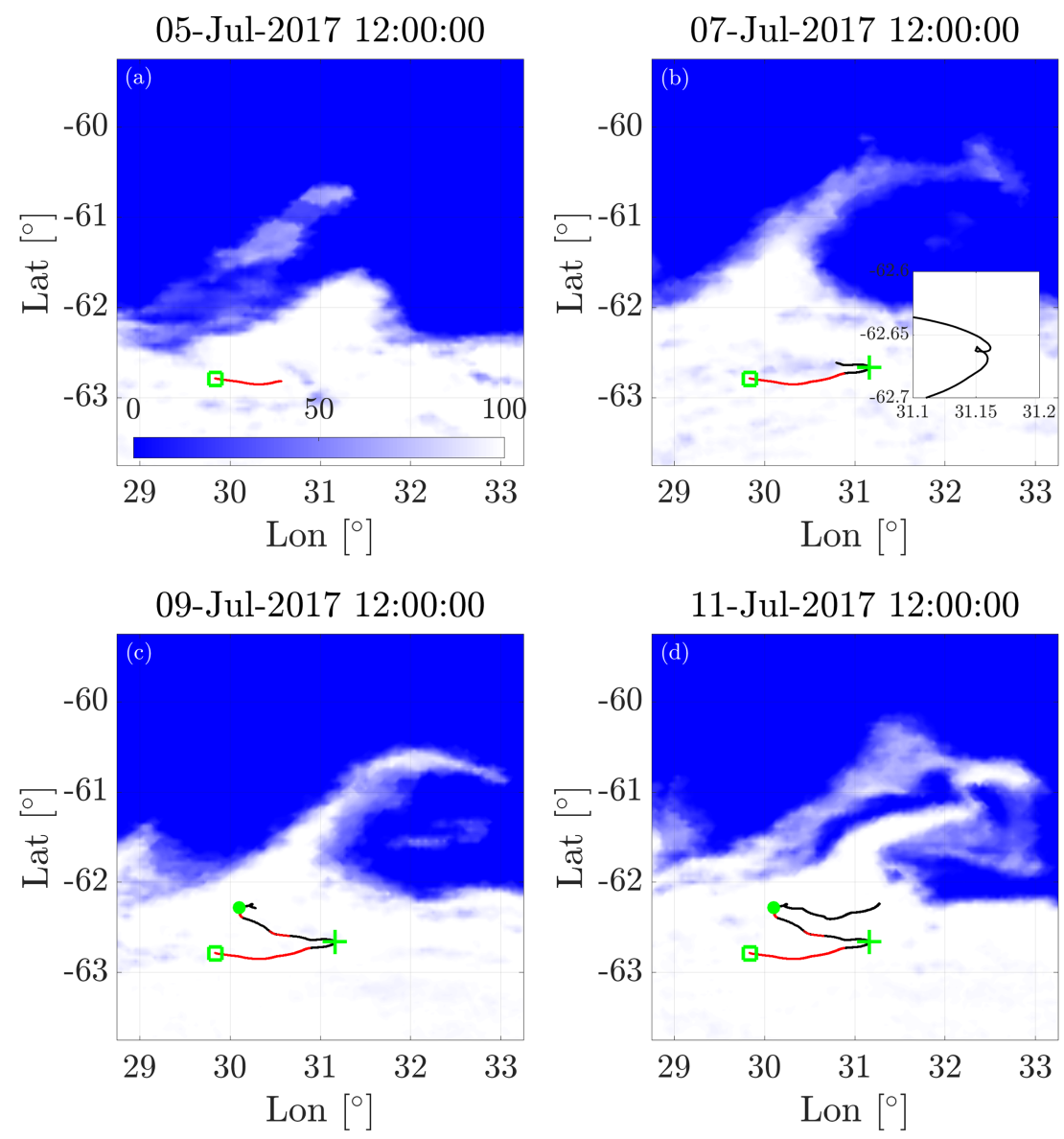

Figure 4. (a-d) Buoy B1 track over 9 days following deployment on 4 July 2017, superimposed on ice concentration. Intervals of intense wave-in-ice activity $\left(H_{S}>1.25 \mathrm{~m}\right.$, chosen arbitrary to separate peaks of $\left.H_{S}\right)$ are highlighted (red). The green square indicates the starting point; the green cross and the green dot indicate the time of transition between phases. The inset in panel (b) is zoomed in view around of the transition from Phase (ii) to Phase (iii).

(At the scale shown, the track of Buoy B2 would overlap the Buoy B1 track.) Over the 9 days we identified three distinct phases of ice movement divided according to the main direction of drift:

i. Over the first 2 days, and driven by the first cyclone during which the wind speed reached $\approx 15 \mathrm{~m} \mathrm{~s}^{-1}$ (to the east), the drift was predominantly eastward, initially with a slight southward component, followed by a slight northward one;

ii. Over the next 2 days, affected by the second cyclone that generated sustained wind of maximum speed $\approx 15 \mathrm{~m} \mathrm{~s}^{-1}$ over a period of $7 \mathrm{hr}$ at the buoys' location, the drift was mainly westward with a slight northward component;

iii. Over the last 4-5 days, affected by the third and fourth cyclones that generated winds of speed $\approx 10 \mathrm{~m} \mathrm{~s}^{-1}$, the drift was roughly eastward, first with a slight southward component and then with a slight northward one, similar to the first phase.

The phases are divided by sharp turning and looping (as shown in the inset of Figure 4b), hence undergoing significant meandering (Gimbert et al., 2012). In total, Buoy B1 drifted $262 \mathrm{~km}$, mainly zonally $(\approx 70 \mathrm{~km}$ for each of three phases) and exhibited a net northward translation $(\approx 80 \mathrm{~km})$. Over the 8 days and $18 \mathrm{hr}$ the average speed was $0.35 \mathrm{~m} \mathrm{~s}^{-1}$, which is over $50 \%$ greater than previously reported daily averages for this sector of the Southern Ocean (Heil \& Allison, 1999). The maximum instantaneous speed was $0.75 \mathrm{~m} \mathrm{~s}^{-1}$, which is the fastest recorded for Antarctic pancake ice drift, to our knowledge.

Figure 4 shows the development of an ice edge feature over time, in the form of a localized protrusion that complicates the interpretation of the distance from the edge shown in Figure 3. We note, however, that the buoys are always in 100\% ice concentration according to remotely sensed AMSR2 ice concentration. 

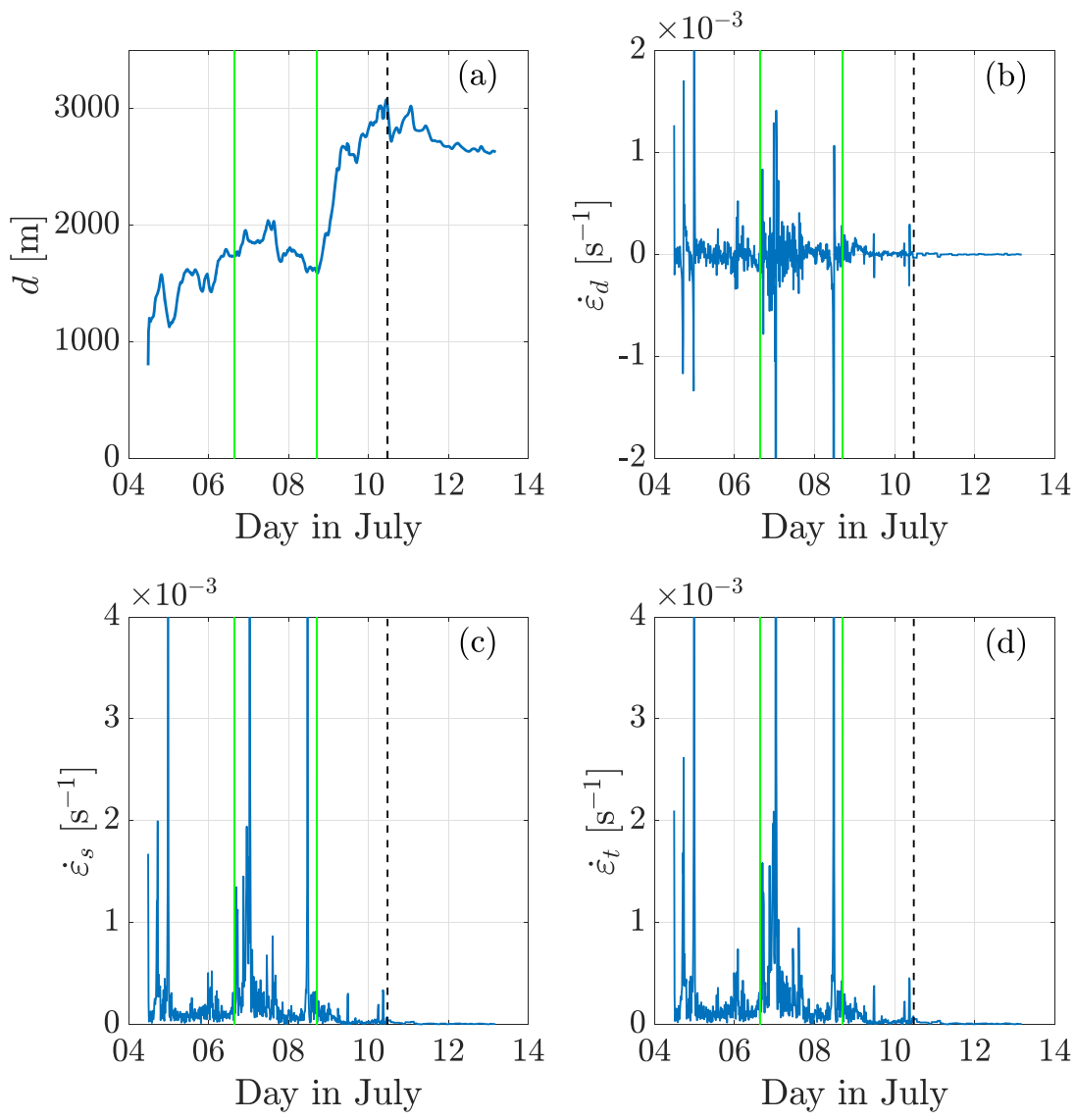

Figure 5. (a) Distance between buoys, (b) divergence rate, (c) shear rate, and (d) total deformation rate. The vertical black dashed line denotes the time when the acquisition rate of the second Buoy B2 was dropped from 15 min to 2 hr to preserve battery life. The green vertical lines indicate the time of transition between phases.

On 11 July (panel d), there are large areas covered by intermediate ice concentration around the protrusion $\left(0 \%<i_{c}<100 \%\right)$, likely due to thermodynamic ice formation, which resulted in the sharp increase in distance between Buoy B1 and ice edge on 11 July shown in Figure 3.

\subsection{Ice Deformations}

Figure 5a shows the time series of the buoy separation distance, $d$. Over the first 4 days from deployment (4-8 July, Phases (i) and (ii)), the buoys slowly drifted apart, reaching a maximum separation of $d=$ 1.5-2 km. Over 8-9 July, at the beginning of Phase (iii), the buoys rapidly drifted apart, from 1.5 to $2.5 \mathrm{~km}$ in less than a day, after which they moved slightly closer. Overall, the distance between the buoys grew by $2 \mathrm{~km}$ over the 9 day measurement period.

Deformations of the sea ice cover are commonly reported in terms of the strain rates (Lindsay, 2002)

$$
\begin{aligned}
\dot{\varepsilon}_{d} & =\frac{\partial u_{i}}{\partial x}+\frac{\partial v_{i}}{\partial y} \\
\dot{\varepsilon}_{s} & =\left[\left(\frac{\partial u_{i}}{\partial x}-\frac{\partial v_{i}}{\partial y}\right)^{2}+\left(\frac{\partial u_{i}}{\partial y}+\frac{\partial v_{i}}{\partial x}\right)^{2}\right]^{1 / 2}, \\
\dot{\varepsilon}_{t} & =\left(\dot{\varepsilon}_{s}^{2}+\dot{\varepsilon}_{d}^{2}\right)^{1 / 2}
\end{aligned}
$$

which are the divergence rate, shear rate, and total deformation rate, respectively. In equation (1), $u_{i}$ and $v_{i}$ denote the ice velocity in the positive east $(x)$ and north $(y)$ directions, respectively, and the spatial derivatives are evaluated using Buoys B1 and B2 velocities $\left(u_{B 1, B 2}\right.$ and $\left.v_{B 1, B 2}\right)$ and position $\left(x_{B 1, B 2}\right.$ and $\left.y_{B 1, B 2}\right)$, for example, $\partial u_{i} / \partial x=\left(u_{B 1}-u_{B 2}\right) /\left(x_{B 2}-x_{B 1}\right)$. Computation of the strain rates over the array of buoys is more accurate than two (Lindsay, 2002), but the loss of accuracy going from an array to only two buoys is unknown. This is a limitation of the current setup. 

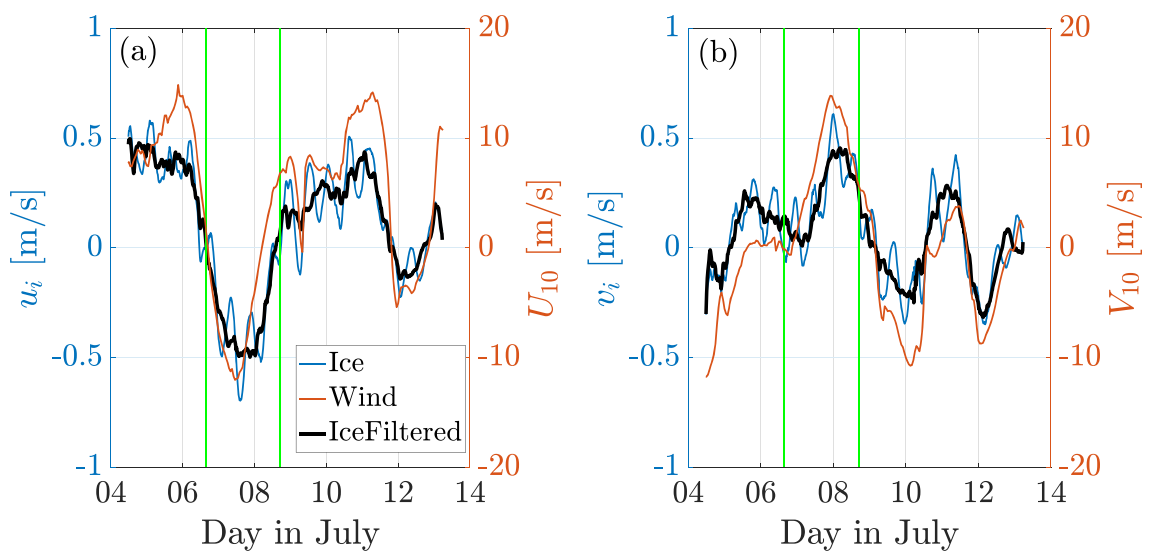

Figure 6. (a) Zonal Buoy B1 velocity (on the left axis) and zonal wind velocity (on the right axis), in black (on the left axis) Buoy B1 zonal velocity when $\approx 13 \mathrm{hr}$ oscillations are excluded. The green vertical lines indicate the time of transition between phases. (b) As in (a) but for meridional velocity component.

Figures $5 b-5 d$ show time series of the strain rates. Divergence and shear intensify at the same time; shear contributes the most to the total strain rate, suggesting that, at the buoy distance length scale, rotational motion dominates over the compression/expansion. The shear to divergence ratio (Shen et al., 1987), $r=\operatorname{atan}\left(\dot{\varepsilon}_{s} / \dot{\varepsilon}_{d}\right)$, characterizes the behavior of the ice continuum ( $r=0$ isotropic divergence, $r=\pi$ isotropic convergence, and $r=\pi / 2$ pure shear). The computed $r$ never exceeds $\pi / 2$, and values are clustered around $r \approx 1$. Note that internal stresses due to collisions are $\approx 0$ for $r$ up to $\approx 1$ (Shen et al., 1987). The strain rates are highly intermittent, which provides further evidence that the ice cover remained unconsolidated, at least until 9 July. The dashed black vertical lines denote the time at which the B2 sampling rate was lowered to $2 \mathrm{hr}$, thus reducing the accuracy of the calculations. Beyond this time, the calculated deformations are significantly lower and intermittent properties disappear due to the coarse temporal resolution.

The root-mean-square (RMS) of the strain rates for the time during which both buoys were recording at a sampling rate of $15 \mathrm{~min}$ are $\dot{\varepsilon}_{d}=7 \times 10^{-4} \mathrm{~s}^{-1}, \dot{\varepsilon}_{s}=1 \times 10^{-3} \mathrm{~s}^{-1}$, and $\dot{\varepsilon}_{t}=1.2 \times 10^{-3} \mathrm{~s}^{-1}$. These are 2-3 orders of magnitude greater than those reported by Doble and Wadhams (2006) for pancake ice in the Weddell Sea, at similar sampling rate of $20 \mathrm{~min}$, but from an array of six buoys with characteristic separation distance of $50 \mathrm{~km}$. The large difference is likely due to the much smaller separation scales of our buoys compared with Doble and Wadhams (2006), as rates of deformation are inversely proportional to the distance between buoys (Doble \& Wadhams, 2006; Rampal et al., 2019), and the strain rates would be comparable if the characteristic distances were equivalent for the same temporal resolution (strain rates would be reduced by lower temporal resolution). Despite the limitation of the current setup, strain rates estimated from the two buoys are similar (when appropriately scaled for distance) to those of Doble and Wadhams (2006) and display similar intermittent behavior.

\subsection{Correlation Between Buoy Drift and Wind}

Figure 6 shows the velocity of Buoy B1 in the zonal (east) and meridional (north) directions, compared to the ERA5 wind colocated at Buoy B1 time and position using a trilinear interpolation (2-D in space, 1-D in time). The ice drift velocity qualitatively follows the wind velocity, but the ice drift includes significant oscillations $\left(\approx 0.125 \mathrm{~m} \mathrm{~s}^{-1}\right)$ of period $\approx 13 \mathrm{hr}$. In Figure $6 \mathrm{a}$, the wind $\left(U_{10}\right)$ and ice velocity $\left(u_{i}\right)$ are positive (to the east) during Phase (i) and become negative (to the west) during Phase (ii).

The wind velocity spectrum (shown in Figure 7) forms a continuous energy cascade, but the ice velocity spectrum exhibits an energy peak (highlighted by the arrow) at a frequency just below two cycles per day $(13.1 \pm 0.85 \mathrm{hr})$. The period of these oscillations is close to the inertial frequency at $62-63^{\circ} \mathrm{S}(13.5 \pm 0.05 \mathrm{hr}$ determined by the Earth's rotation).

Figure 8a shows Buoy B1 speed, obtained from the two velocity components shown in Figure 6, compared to the ERA5 wind speed. The instantaneous drift speed peak of $0.75 \mathrm{~m} \mathrm{~s}^{-1}$ occurs during Phase (ii), at midnight between 7 and 8 July 2017. The wind speed at that instant is $14 \mathrm{~m} \mathrm{~s}^{-1}$, and the peak wind speed of $15 \mathrm{~m} \mathrm{~s}^{-1}$ occurs at 16:00 on 7 July. During the transition between Phases (i) and (ii), denoted by first vertical line in Figure 8 , the wind stops; that is, both the north and east components of the wind velocity approach $0 \mathrm{~m} \mathrm{~s}^{-1}$ 

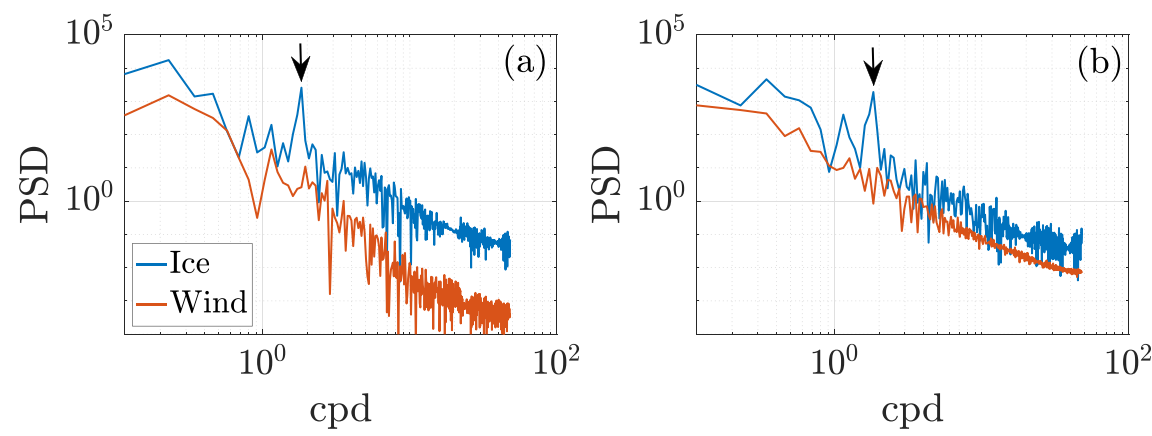

Figure 7. (a) Spectra corresponding to the zonal Buoy B1 velocity (blue) and zonal wind velocity (orange). An arbitrary vertical shift is applied to the wind spectra to aid comparison. Black arrows denote the peak associated to inertial-like oscillations ( $\approx 13 \mathrm{hr}$ ). (b) As in (a) but for meridional velocity component.

(see Figure 6), and the ice drift almost stops. The correlation between the wind and Buoy B1 speed is $R^{2}=$ 0.56 ; this increases to $R^{2}=0.66$ when inertial-like oscillations are filtered out on the zonal and meridional components (black curves in Figures 6 and 8). The wind factor, that is, the ratio of ice speed to wind speed, estimated with a standard least squares regression is $3.3 \%$ (3.3 $\pm 0.05 \%$, confidence interval $95 \%)$. This value is consistent with the value of 3-3.5\% (with $R^{2}=0.5$ ) in pancake ice in the Weddell Sea, reported by (Doble \& Wadhams, 2006). Little to no correlation is found between the ice drift and the wave-in-ice activity $\left(R^{2}<0.1\right)$, even during the periods of large significant wave heights $\left(H_{S}>1.25 \mathrm{~m}\right.$; this threshold captures the highest peaks, but results are unchanged if the threshold is lowered down to $1 \mathrm{~m}$; see Figure 3), suggesting that wave-induced drift of pancake floes is negligible in comparison to wind-induced drift. However, we note that the wind factor is marginally higher $(3.7 \% ; 3.7 \pm 0.07 \%, 95 \%$ confidence interval) during period of large waves, which are always associated with strong winds.

Figure $8 \mathrm{~b}$ shows the angle $\theta_{0}$ between the ice drift and the wind direction. Previous observations indicate the angle, on average, to be in the range $0-30^{\circ}$, positive in the Northern Hemisphere and negative in the Southern Hemisphere (Leppäranta, 2011). The present data set gives a mean angle $\approx-25^{\circ}$, as shown by the dashed line and with generally large
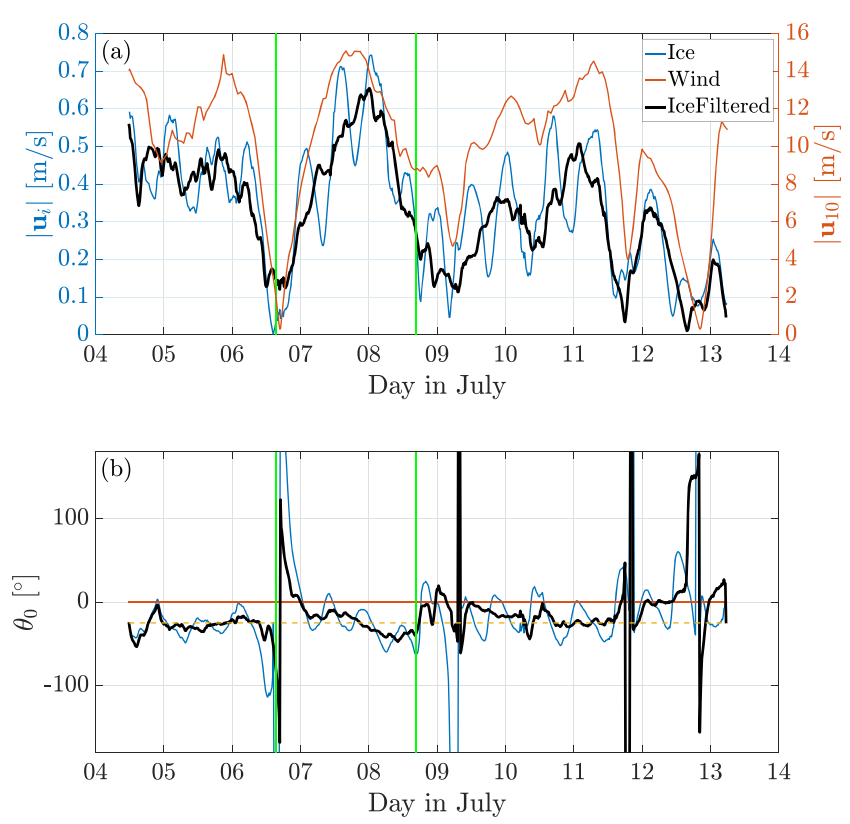

Figure 8. (a) Buoy B1 speed (left axis) in total (blue) and with $\approx 13 \mathrm{hr}$ oscillations are excluded (black) and total wind speed (right axis; orange). (b) Difference between ice and wind direction $\theta_{0}$ (blue), difference when $\approx 13 \mathrm{hr}$ oscillations are excluded (black), and the mean difference $-25^{\circ}$ (yellow dashed). The green vertical lines indicate the time of transition between phases. variations from $-60^{\circ}$ to $10^{\circ}$. The large variations are consistent with, for example, Lund et al. (2018), who reported turning angles from $-23^{\circ}$ to $+83^{\circ}$ during a storm event in the Arctic Basin and in other instances reported ice drift against the wind (turning angle $>90^{\circ}$ ). During our measurements, the largest angles between wind and ice direction $\left(\left|\theta_{0}\right|>90^{\circ}\right)$ occur sporadically and are always observed for low wind speed $\left(\left|\mathbf{u}_{10}\right|<\right.$ $6 \mathrm{~m} \mathrm{~s}^{-1}$ ), when the wind stresses become small.

\section{Pancake Ice Drift Model}

\subsection{Model Formulation}

The Arctic Ice Dynamics Joint Experiment (AIDJEX) model for sea ice drift (Coon et al., 1974; Feltham, 2008; Leppäranta, 2011) is

$$
m_{i} \frac{d \mathbf{u}_{i}}{d t}=A_{i} \mathbf{S}_{a}+A_{i} \mathbf{S}_{w}+m_{i} \mathbf{S}_{c}+m_{i} \mathbf{S}_{g}+\nabla \cdot \sigma,
$$

where $m_{i}, A_{i}$, and $u_{i}$ are, respectively, the mass, area, and velocity of the ice; $S_{a}, S_{w}, S_{c}$, and $S_{g}$ are external stresses due to wind, ocean currents, Coriolis, and ocean tilt, respectively; and $\nabla \cdot \sigma$ is the rheology that defines internal stresses. The ice mass is $m_{i}=\rho_{i} h_{i} A_{i}$, where $\rho_{i}$ is the ice density and $h_{i}$ its thickness.

As stated in section 2, in situ observations of the ice concentration during deployment were $100 \%$ ( $\approx 60 \%$ pancake floes and the remaining $40 \%$ interstitial frazil ice). The wave-in-ice activity $\left(H_{S}\right)$ measured by the buoys during the subsequent days indicates that similar unconsolidated conditions were maintained. On this basis, the free drift regime is assumed 
$(\nabla \cdot \sigma=0)$, as is standard for low ice concentration (Herman, 2012; Hunke et al., 2010) and for which wind and ocean stresses should be appropriately scaled using the ice concentration itself (Connolley et al., 2004).

A quadratic wind stress is used, of the form

$$
\mathbf{S}_{a}=C_{a} \rho_{a}\left|\mathbf{u}_{a}^{\prime}\right| \mathbf{u}_{a}^{\prime} \exp \left(\mathrm{i} \theta_{a}\right),
$$

where $C_{a}$ is the wind drag coefficient over ice, $\mathbf{u}_{a}^{\prime}$ the velocity difference between the wind and the ice $\left(\mathbf{u}_{a}^{\prime}=\mathbf{u}_{a}-\mathbf{u}_{i}\right), \rho_{a}$ the air density, $\theta_{a}$ is the angle between the wind direction and the wind-induced stress, and $\mathrm{i}$ is the imaginary unit $\left(\mathrm{i}^{2}=-1\right)$. Linear formulations and calibrated exponents have been used (Martinson \& Wamser, 1990), but only the more common quadratic formulation is discussed herein.

For consistency, a quadratic ocean drag is also adopted (Leppäranta, 2011), with

$$
\mathbf{S}_{w}=C_{a} \rho_{w}\left|\mathbf{u}_{w}^{\prime}\right| \mathbf{u}_{w}^{\prime} \exp \left(\mathrm{i} \theta_{w}\right),
$$

where

$$
\mathbf{u}_{w}^{\prime}=\mathbf{u}_{w}+\mathbf{u}_{g}-\mathbf{u}_{i}
$$

assuming ocean and geostrophic currents of velocity $\mathbf{u}_{w}$ and $\mathbf{u}_{g}$, respectively. We note that in absence of currents, $\mathbf{u}_{w}=\mathbf{u}_{g}=0$, the ocean drag would be proportional to the ice speed and act in the opposite direction to the ice drift, that is, $\mathbf{u}_{w}^{\prime}=-\mathbf{u}_{i}$, so that it produces damping.

The term $\mathbf{S}_{c}$ denotes the Coriolis stress; in absence of other external forces, it produces rotation, which is leftward in the Southern Hemisphere with respect to the direction of the ice drift. The Coriolis stress is expressed as (Cushman-Roisin \& Beckers, 2011)

$$
\mathbf{S}_{c}=-\mathrm{i} f \mathbf{u}_{i},
$$

where $f=2 \omega \sin (\psi)$ is the Coriolis parameter, in which $\omega=7.2921 \times 10^{-5} \mathrm{rad} \mathrm{s}^{-1}$ denotes the Earth's rotation rate and $\psi$ is latitude.

The stress due to the ocean slope, $\mathbf{S}_{g}$, is written (Leppäranta, 2011) as

$$
\mathbf{S}_{g}=-\nabla \zeta,
$$

where $\zeta$ denotes the sea surface height. In deep water this term can be expressed as a function of the surface geostrophic current (Cushman-Roisin \& Beckers, 2011), with

$$
\mathbf{S}_{\mathrm{g}}=\mathrm{i} f \mathbf{u}_{\mathrm{g}},
$$

which is similar in form to $\mathbf{S}_{c}$ but does not depend on the ice velocity.

The AIDJEX model, equation (2), becomes

$$
\frac{\mathrm{d} \mathbf{u}_{i}}{\mathrm{~d} t}=\alpha \mathbf{u}_{a}^{\prime}\left|\mathbf{u}_{a}^{\prime}\right| \exp \left(\mathrm{i} \theta_{a}\right)+\beta \mathbf{u}_{w}^{\prime}\left|\mathbf{u}_{w}^{\prime}\right| \exp \left(\mathrm{i} \theta_{w}\right)-\mathrm{i} f \mathbf{u}_{i}+\mathrm{i} f \mathbf{u}_{g},
$$

where

$$
\alpha=\frac{\rho_{a} C_{a}}{\rho_{i} h_{i}} \quad \text { and } \quad \beta=\frac{\rho_{w} C_{w}}{\rho_{i} h_{i}}
$$

The Nansen number (the ratio between wind and ocean stresses) can be expressed in terms of the coefficients $\alpha$ and $\beta$, as

$$
N a=\sqrt{\frac{\rho_{a} C_{a}}{\rho_{w} C_{w}}}=\sqrt{\frac{\alpha}{\beta}},
$$

which indicates the wind stress effect on sea ice drift, explicitly accounting for the air and water drag ratio. Equation (9) is equivalent to the free drift model given by Leppäranta (2011), their equation (6.3), with the advective acceleration conserved to maintain the generality of our formulation.

\subsection{Model Setup}

Equation (9) is numerically solved in a Lagrangian frame of reference to simulate the buoy drift, using a finite difference, time stepping method. Time steps of $60 \mathrm{~s}$ were found to give sufficient convergence. At each step, the velocity and displacement are computed, and the buoy advanced in space. 

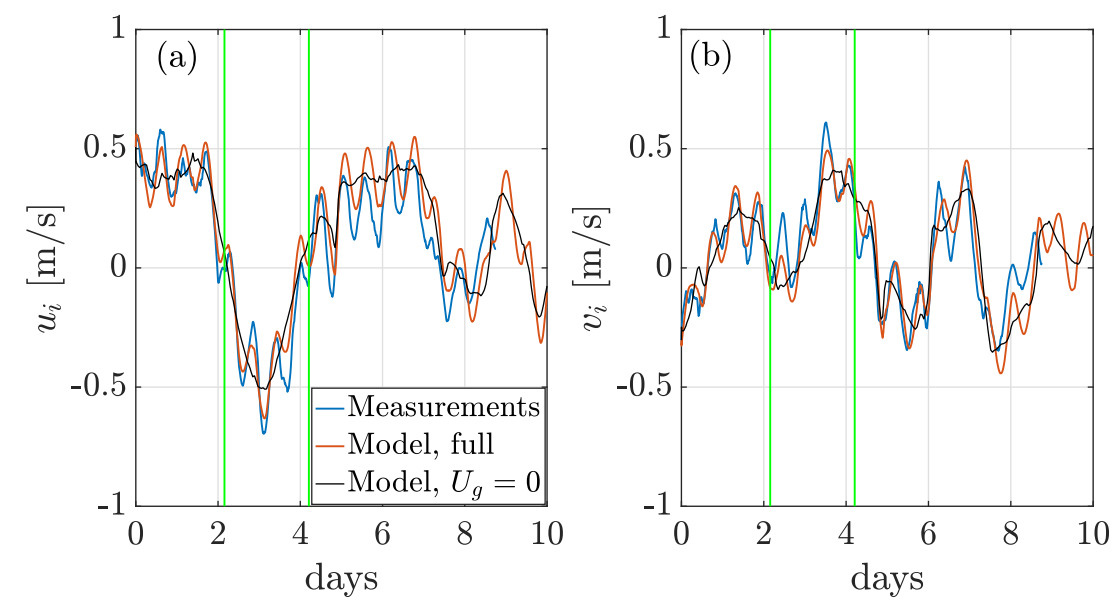

Figure 9. Time series of Buoy B1 measurements (blue) and model simulations, for full model (orange) and $U_{g}=0$ (black): (a) zonal velocity and (b) meridional velocity. The green vertical lines indicate the time of transition between phases.

Wind forcing is retrieved from ERA5 and, at each time step, interpolated in space and time onto the simulated buoy position. No data are available on ocean currents-in general, currents are rarely available in ice-covered regions (Nakayama et al., 2012)—thus, $\mathbf{u}_{w}=0$ is set. The strong signature of the measured drift at periods close to the inertial range is likely related to the geostrophic current, as the contribution of $m_{i} \mathbf{S}_{c}$ is negligible for the thin sea ice in the Antarctic MIZ (Martinson \& Wamser, 1990) and only becomes relevant for multiyear ice $\left(h_{i}>1 \mathrm{~m}\right)$.

Based on the buoy drift measurements, we adopt the geostrophic term to be a rotational term of the type

$$
\mathbf{u}_{g}=U_{g} \exp (\mathrm{i} f t)
$$

where the amplitude of the near-inertial oscillations $U_{g}$ is estimated from the measurements to be $U_{g}=$ $0.125 \mathrm{~m} \mathrm{~s}^{-1}$, which is the mean amplitude of the oscillations in 12-14 hr identified utilizing a band-pass filter. We set $\theta_{a}=0$ and $\theta_{w}=-25^{\circ}$, in agreement with the AIDJEX formulation when surface winds (at a standard height of $10 \mathrm{~m}$ above ground) are used (Leppäranta, 2011), noting that $\theta_{w} \approx \theta_{0}$ (Leppäranta, 2011).

The remaining free parameters, $\alpha$ and $\beta$, are calibrated by matching model velocity outputs with the measurements, by minimizing the difference $\left|u_{i}^{O}-u_{i}^{M}\right|+\left|v_{i}^{O}-v_{i}^{M}\right|$ (or $L_{1}$ norm), where superscripts $O$ and $M$ denote the observations (measurements) and the model, respectively. The objective function can be defined differently. The $L_{2}$ norm (or Euclidean distance) would favor higher velocities; on the other hand, normalization by the instantaneous speed would favor low velocities (for speed tending to 0 , the distance between measurements and model tend to infinity, even for small absolute errors). Therefore, we use the $L_{1}$ norm that is the most balanced way to define distance between vectors.

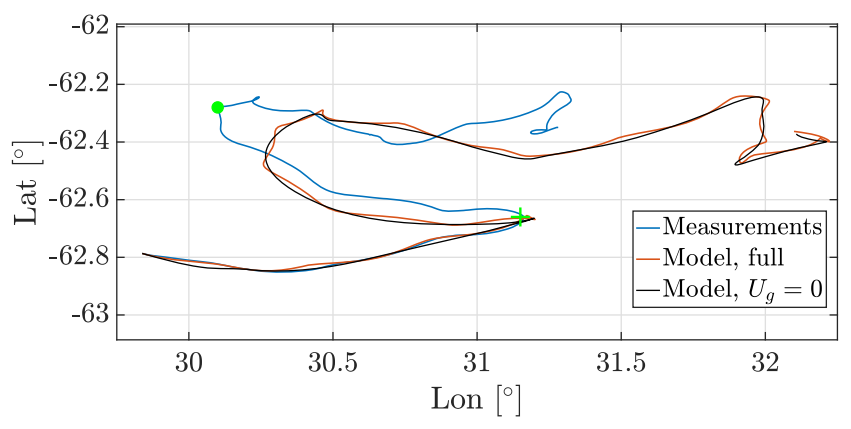

Figure 10. Buoy B1 tracks from measurements (blue) compared to model simulations (full model, orange; $U_{g}=0$, black). The green cross and the green dot indicate the time of transition between phases.
We test values of $\alpha$ in the range $0.012-0.015 \times 10^{-3} \mathrm{~m}^{-1}$, which corresponds to $C_{a}$ in 3.0-3.7 $\times 10^{-3}$, as identified by Overland (1985) for the MIZ, and $\rho_{i}=910 \mathrm{~kg} \mathrm{~m}^{-3}, \rho_{a}=1.3 \mathrm{~kg} \mathrm{~m}^{-3}$, and $h_{i}=0.35 \mathrm{~m}$, the latter being obtained from visual observations during in situ operations. Similarly, we test values of $\beta$ in the range $5-16 \times 10^{-3} \mathrm{~m}^{-1}$, which corresponds to $C_{w}$ in 1.6-5.0 $\times 10^{-3}$ and $\rho_{w}=1,028 \mathrm{~kg} \mathrm{~m}^{-3}$. The lower and upper limits for $C_{w}$ are taken from values reported by Martinson and Wamser (1990) in the Weddell Sea and McPhee (1982) in the Beaufort Sea, respectively. The calibrated parameters are $\alpha=0.0128 \times 10^{-3}$ and $\beta=8.9 \times 10^{-3} \mathrm{~m}^{-1}$.

\subsection{Model Results}

Figure 9 shows model results against measurements for the zonal (a) and meridional (b) velocity components. Model outputs are shown for both $U_{g}=0.125 \mathrm{~m} \mathrm{~s}^{-1}$ (full model) and $U_{g}=0$, to highlight the effect of the geostrophic term. Suppression of the geostrophic term $\left(U_{g}=0\right)$ 

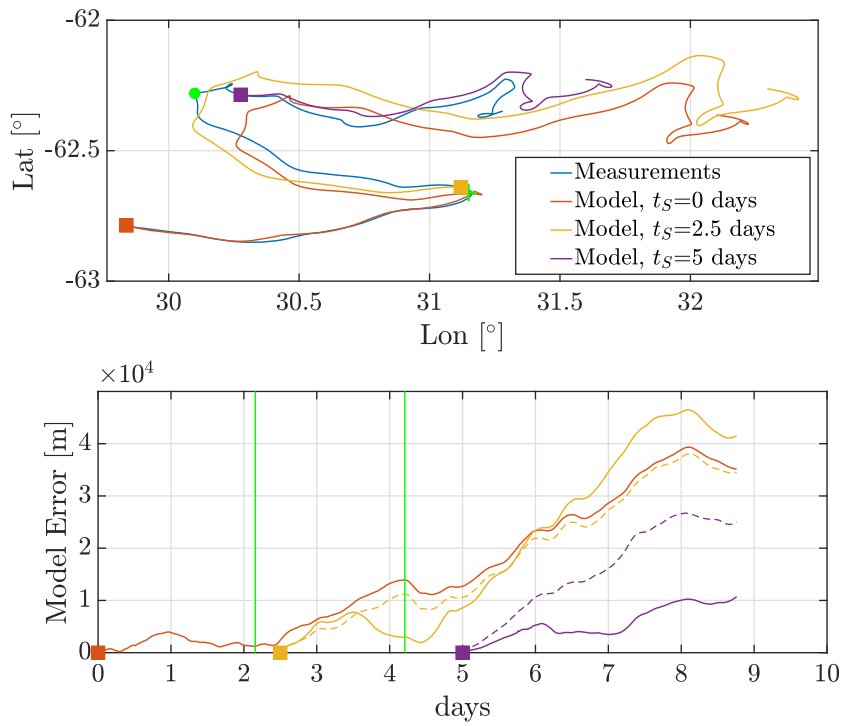

Figure 11. (a) As in Fig 10 but for three different start times $\left(t_{S}\right.$, indicated by filled squares) and corresponding tuned parameters $\alpha$ and $\beta$. The green cross and the green dot indicate the time of transition between phases.

(b) Time series of errors for model calibrated for each new start time (solid curves), compared to errors when overall calibrated parameters are used (dashed curves). The green vertical lines indicate the time of transition between phases. eliminates near-inertial, $13 \mathrm{hr}$ period oscillations, and the time series resembles the band-pass filtered measurements (black line in Figure 6). Model predictions when the geostrophic term is included broadly agree with the measurements, although some of the high-frequency oscillations observed in the measurements are not captured. Differences between measurements and model outputs are likely due to relatively low temporal and spatial resolution of the input ERA5 wind data, which results in a smooth wind field, without small-scale variability. The root-mean-square error over the entire duration of the measurements is $0.095 \mathrm{~m} \mathrm{~s}^{-1}$ for the full model and grows to $0.125 \mathrm{~m} \mathrm{~s}^{-1}$ by suppressing the geostrophic term, in both the meridional and the zonal velocity components.

Figure 10 shows the measured and simulated buoy tracks. The full model accurately reproduces Buoy B1 drift during Phase (i), in which the drift is eastward. After a loop at the end of Phase (i), that is, at the location denoted by a green cross in Figure 10, the model underpredicts the maximum westward movement remaining to the east of the measured buoy position during Phases (ii) and (iii). Meanders, cycloids (the half moon-shaped part of the track connected by cusps), and loops (during which the rotational component of the motion, driven by the geostrophic forcing, dominates over momentarily weak wind drag) of the Buoy B1 track are qualitatively reproduced only when the geostrophic current is included.

Figure 11a shows model results that start at $t_{S}=0,2.5$ and 5 days from the start of measurements, noting that $t_{S}=2.5$ days is $\approx 6 \mathrm{hr}$ into Phase (ii) and $t_{S}=5$ days is $\approx 18 \mathrm{hr}$ into Phase (iii). For the three different start times, parameters $\alpha$ and $\beta$ are calibrated over the following: $t_{S}=0$ till the end of Phase (i), $t_{S}=2.5$ days till the end of Phase (ii), and $t_{S}=5$ days till the end of Phase (iii). Parameters $\alpha$ and $\beta$ are given in Table 1, noting that the parameters for $t_{S}=0$ (Phase (i)) are almost identical to the ones calibrated over the entire track. Compared to Phase (i), the coefficients $\alpha$ and $\beta$ increase during Phase (ii) and decrease during Phase (iii), noting that $\alpha$, which is related to the ice surface roughness (Johannessen et al., 1983), is the parameter with the highest variability ( $> \pm 50 \%$ relative to Phase (i); see Table 1$)$.

Figure $11 \mathrm{~b}$ shows the time series of model errors corresponding to Figure 11a, that is, distances between the model and measured positions, for the start times $t_{S}=0,2.5$, and 5 days. It also includes errors for the start times $t_{S}=2.5$ and 5 days, without recalibration of $\alpha$ and $\beta$. The error for $t_{S}=0$ days $\left(\alpha=0.0128 \times 10^{-3}\right.$ and $\beta=8.9 \times 10^{-3} \mathrm{~m}^{-1}$ ) is $<5 \mathrm{~km}$ during Phase (i) and only exceeds this threshold at 2.75 days. The error then steadily grows (during Phases (ii) and (iii)), up to $\approx 40 \mathrm{~km}$ at 8 days, due to error propagation in the time integration, and changes in the optimal values of $\alpha$ and $\beta$. The error for $t_{S}=2.5$ days $\left(\alpha=0.0225 \times 10^{-3}\right.$ and $\beta=11.6 \times 10^{-3} \mathrm{~m}^{-1}$ ) never exceeds $7.5 \mathrm{~km}$ during Phase (ii), and at the end of Phase (ii) the model error is $<3 \mathrm{~km}$. For comparison, utilizing parameters calibrated over the entire track the error at the end of Phase (ii) is $\approx 11 \mathrm{~km}$, that is, 4 times larger than the model error with dedicated parameters. The error for $t_{S}=5$ days $\left(\alpha=0.0061 \times 10^{-3}\right.$ and $\left.\beta=7.4 \times 10^{-3} \mathrm{~m}^{-1}\right)$ is only $3.4 \mathrm{~km}$ after 2 days and remains $<11 \mathrm{~km}$ till the end of Phase (iii). This is significantly better than the model's prediction for $t_{S}=5$ days and parameters calibrated over the entire track, which, for example, result in an error of $27 \mathrm{~km}$ after 3 days.

Table 1

Calibrated Parameters for the Start Times $t_{s}=0,2.5$, and 5 Days (Roughly Phases (i)-(iii), Respectively)

\begin{tabular}{lccc}
\hline & $\alpha \times 10^{-3}\left(\mathrm{~m}^{-1}\right)$ & $\beta \times 10^{-3}\left(\mathrm{~m}^{-1}\right)$ & $N a \times 10^{-2}(-)$ \\
\hline Phase (i) & $0.0128(-)$ & $8.9(-)$ & $3.81(-)$ \\
Phase (ii) & $0.0225(+75.8 \%)$ & $11.6(+30.3 \%)$ & $4.40(+15.5 \%)$ \\
Phase (iii) & $0.0061(-52.3 \%)$ & $7.4(-16.9 \%)$ & $2.87(-24.7 \%)$ \\
\hline
\end{tabular}

Note. The values in parenthesis for Phases ((ii)-(iii)) show the variation compared to Phase (i). 


\section{Discussion}

Pancake ice is the dominant formation mechanism of sea ice around Antarctica, and it is becoming more common in the emerging Arctic MIZ (Wadhams et al., 2018). Thermodynamics and dynamics of pancake ice govern the atmosphere-ocean-sea ice momentum and mass exchanges over vast ice-covered areas, thus playing a role in the global climate system (Doble et al., 2003; Smith et al., 2018).

This study is the first to measure and analyze both the drift of pancake ice floes and concomitant wave activity, during a series of intense winter polar cyclones. The analysis is based on the assumption that pancake ice conditions persisted over the 9 days following deployment. Cyclonic activity and associated intense wave-in-ice activity prevents consolidation of pancake ice floes (Doble \& Wadhams, 2006; Shen et al., 2004). Their absence has been used to infer consolidation of the pancakes into a compact ice cover (Doble \& Wadhams, 2006). Our measurements of energetic waves $\left(H_{S}>1.25 \mathrm{~m}\right)$ and intermittent internal sea ice deformations 100-200 km from the ice edge suggest that pancake ice conditions similar to the ones at deployment (Alberello, Onorato, Bennetts, et al., 2019) persisted for at least the first 7 days following deployment, beyond which ice conditions may have transformed as the ice edge advanced.

By calibrating $C_{a}$ and $C_{w}$ properly, free drift with no internal stress or wave effect, as might be caused by Stokes drift (Yiew et al., 2017), slope sliding (Grotmaack \& Meylan, 2006), or wave radiation stresses (Masson, 1991), produces very good model results compared with observations, especially under storm conditions. Williams et al. (2017) and Boutin et al. (2019) recently integrated wave radiation stresses into large-scale numerical models that include wave attenuation and wave-induced ice breakup, based on the wave-ice interaction model of Williams et al. (2013a, 2013b). They found that large wave radiation stresses, proportional to the wave attenuation rate, remain concentrated at the edge (Williams et al., 2017); wind and ocean stresses dominate ice drift over longer distances. Moreover, Williams et al. (2017) found that wave radiation stresses are appreciable only for wave periods $<10 \mathrm{~s}$; the measurements reported here have dominant periods $>15 \mathrm{~s}$. The small floes observed during our measurements, smaller floes than tested by Williams et al. (2017), would induce even weaker radiation stresses. Although wave-induced drift is negligible, it is expected that the significant waves measured will have induced turbulence in the water sublayers (Alberello, Onorato, Frascoli, et al., 2019; Smith \& Thomson, 2019; Zippel \& Thomson, 2016), enhancing mixing and heat fluxes under sea ice (Ackley et al., 2015; Smith et al., 2018).

Shen et al. (1987) proposed a granular rheology for the MIZ based on momentum transfer through floe-floe collisions. Feltham (2005) used the collisional rheology in a compositive MIZ/pack ice rheology. In comparison, Sutherland and Dumont (2018) used a rheology based on Mohr-Coulomb granular theory, and their model outputs and field measurements showed strong wave attenuation and ice deformation that resulted in rafting of the floes. Notably, the ice drift was constrained by the coast, allowing for the internal stresses to build up (Dai et al., 2004). Although the shear to divergence ratio in our data (which should be computed using an array of sensors for greater accuracy) does not completely rule out effects of collisions on internal stresses, its value is typically lower than the threshold for significant stresses (Shen et al., 1987). Moreover, the model-data agreement shown in section 4.3, without a rheology term, indicates that internal stresses are negligible for pancake ice during intense cyclones, and no collisions or rafting were observed during deployment. This is consistent with laboratory wave basin experiments reported by Bennetts and Williams (2015), which showed negligible attenuation, and although regular floe-floe collisions occurred, they were weak and did not result in rafting. Discrete element models of pancake ice floes in waves (Hopkins \& Shen, 2001; Sun \& Shen, 2012) also show that no rafting occurs in an open boundary configuration but it does when waves push the floes against a fixed boundary (Dai et al., 2004).

Drift measurements conducted at high temporal resolution generated accurate estimates of the drift speed (Thorndike, 1986) during the passage of intense cyclones. The speed reached $\approx 0.75 \mathrm{~m} \mathrm{~s}^{-1}$, which is the highest ice speed ever recorded in the Southern Ocean to our knowledge. Evaluation of the drift speed is sensitive to the sampling rate (Thorndike, 1986), and daily or subdaily measurements, available using remote sensing products (e.g., OSI-SAF Lavergne et al., 2010), can underestimate the maximum ice drift speed by over $20 \%$, making them unsuitable to study drift at small temporal scales. A detailed analysis of our data indicates that the maximum speed is reduced by $\approx 5 \%$ when the sampling is lowered to $6 \mathrm{hr}$ and by $\approx 20 \%$ for $12 \mathrm{hr}$ sampling. Velocity components in the north and east directions show larger reductions. Previously reported measurements at a $6 \mathrm{hr}$ sampling rate or greater (Heil \& Allison, 1999; Martinson \& Wamser, 1990; Vihma et al., 1996) might have underestimated the instantaneous drift speed and, consequently, provided 
lower estimates of the drag coefficients and wind factors over sea ice. The 15 min sampling seems to accurately capture ice velocity (the velocity is almost invariant for sampling $\leq 1 \mathrm{hr}$ ), but an even higher temporal resolution would be needed to verify this hypothesis.

Low temporal resolution drift measurements would not have captured the oscillations with period close to the inertial range; at least a $3 \mathrm{hr}$ resolution is needed to capture these oscillations. The rotational motion significantly contributes to instantaneous ice speed and induces instantaneous ice drift in opposition to the wind direction, when the wind intensity drops. The model outputs indicate that geostrophic forcing is responsible for the observed oscillations, that is, model results omitting geostrophic forcing do not reproduce the observed velocity oscillations, even for thicker ice, up to $1 \mathrm{~m}$. Moreover, tidal currents have previously been found to affect ice drift only in limited water depth conditions (Mack et al., 2013; Meyer et al., 2017; Padman et al., 2018; Peterson et al., 2017), especially in shelf seas and coastal areas and, therefore, are unlikely to be the source of the periodic oscillations since the study area is located in deep waters (Arndt et al., 2013) where tidal currents are small. Instead, combined measurements and model outputs support the existence of a geostrophic-like forcing at period close to $13 \mathrm{hr}$, similar to the indirect observations of Lund et al. (2018) in the Arctic. The rotational motion period and amplitude ( $\approx 2 \mathrm{~km}$ in diameter), similar to submesoscale eddies that have been found to form at the edge of the MIZ in the Arctic (Lund et al., 2018) and in numerical experiments (Dai et al., 2019; Manucharyan \& Thompson, 2017), are likely driven by wind-forced near-inertial motion of the upper ocean in this case (Howard et al., 2004).

Our analysis indicates that the ratio $C_{a} / C_{w}$, using a quadratic drag formulation, is order unity for pancake ice in the Southern Ocean winter MIZ: This value is obtained using $\rho_{i}=910, \rho_{a}=1.3$, and $\rho_{w}=1,028 \mathrm{~kg} \mathrm{~m}^{-3}$ and $h_{i}=0.35 \mathrm{~m}$ estimated at deployment, which gives $C_{a}=0.0032$ and $C_{w}=0.0027$. The values for the drag coefficients are close to those found in the MIZ by Overland (1985), Martinson and Wamser (1990), McPhee (1982), and Leppäranta (2011), noting that none of previously reported drag coefficients explicitly refers to pancake ice. Moreover, sea ice drag coefficients do not account for roughness due to ocean waves propagating in the MIZ, which remains an open problem (Zippel \& Thomson, 2016). A larger database of concurrent ice conditions, drift, and wave-in-ice properties is needed to verify how storm conditions affect drag coefficients.

Leppäranta (2011) argues that the ratio $C_{a} / C_{w}$ does not vary for all ice types because the ice roughness on the air and water sides is correlated, and hence, the Nansen number $N a=\sqrt{\alpha / \beta} \propto \sqrt{C_{a} / C_{w}}$ does not vary (assuming air and water densities are constant). Model calibrations of the parameters $\alpha$ and $\beta$ suggest some variation over the 9 days following deployment, but a more robust statistical analysis would be needed. We obtain $N a=0.0381$ in Phase (i), $N a=0.0440$ in Phase (ii), and $N a=0.0287$ in Phase (iii). Variation of the Nansen number indicates a corresponding change of the ratio $C_{a} / C_{w}$, suggesting the ice conditions modified 2 days after deployment, that is, at the transition from Phase (i) to Phase (ii) and again after 4 days, that is, at the transition from Phase (ii) to Phase (iii). Phase (iii) is characterized by less intense wave-in-ice activity and significantly slower drift. The drift behavior in Phase (iii) is likely associated with the ice being more consolidated than in Phases (i) and (ii), so that internal stresses may influence ice dynamics. This also explains the poorer agreement between the free drift model and Phase (iii) measurements, even after calibration. In fact, the Nansen number is defined by two parameters that are calibrated by matching model outputs with measurements. Therefore, the calibrated parameter values also account for mismatch of model with observations due to processes missing in the model. Variation in the parameter values for different phases may reflect that processes not included in the model are becoming nonnegligible. Moreover, model calibrations crucially depend on the input wind and currents, and we recall that no data on currents are available for our experiments, and a thorough analysis of ERA5 wind bias in ice-covered regions is needed.

\section{Conclusions}

High temporal resolution measurements of drift of a pair of buoys deployed on pancake floes, initially $100 \mathrm{~km}$ into the MIZ, during the Antarctic winter expansion were analyzed over a 9 day period, over which four polar cyclones impacted the ice cover. The measurements, and comparisons with a calibrated Lagrangian free drift model, revealed that

- Pancake ice floes in the MIZ are extremely mobile, even in $100 \%$ ice concentration (60\% pancake ice and $40 \%$ interstitial frazil ice). The maximum instantaneous ice drift speed was $0.75 \mathrm{~m} \mathrm{~s}^{-1}$, measured 
during intense storm conditions (winds up to $\approx 15 \mathrm{~m} \mathrm{~s}^{-1}$ ), and exceeding previously reported values for the ice-covered Southern Ocean.

- Pancake ice drift velocity correlates very well with wind velocity, indicating that wind is the dominant forcing, except for a strong inertial-like signature at $\approx 13 \mathrm{hr}$ in the drift, which was attributed to geostrophic currents. Despite the strong wave-in-ice activity, no correlation was found with the measured ice drift.

- A free drift model accurately predicts pancake ice drift velocities, indicating that internal stresses are negligible. This finding was backed by the relative motion between the buoys, which was 2 orders of magnitude smaller than the total drift.

- The Nansen number varied considerably over the 9 days period at the scale of synoptic events (2-3 days), suggesting that ice conditions and, consequently, ocean and wind drag have changed, although it may also be due to inaccuracies in the model forcings used.

Present results highlight the need for better understanding and modeling of $\alpha$ and $\beta$ (equivalently, the drag coefficients and ice thickness) and their temporal and spatial variation, together with reliable wind and current data. This will empower accurate predictions of pancake ice drift in the MIZ at the 2-3 day temporal scale of synoptic events, particularly during polar cyclones that continuously reshape the MIZ and have the largest effect on the advance and retreat of pancake ice around Antarctica.

\section{Acknowledgments}

The expedition was funded by the South African National Antarctic Programme through the National Research Foundation. This work was partially funded by the ACE Foundation and Ferring Pharmaceuticals. A. A., L. B., A. T., and P. H. were supported by the Australian Antarctic Science Program (all by Project 4434 and PH by Projects 4301 and 4390). M. O. was supported by the Departments of Excellence20182022 Grant awarded by the Italian Ministry of Education, University and Research (MIUR) (L.232/2016). C. E. was supported under NYUAD Center for Global Sea Level Change ProjectG1204. P. H. was supported by the Australian Governments Cooperative Research Centres Programme through the Antarctic Climate and Ecosystems Cooperative Research Centre. We are indebted to Captain Knowledge Bengu and the crew of the SA Agulhas II for their invaluable contribution to data collection. We thank the two anonymous reviewers; their comments improved the original submitted manuscript. ERA5 reanalysis was obtained using Copernicus Climate Change Service Information 2019. A. A. and A. T. acknowledge support from the Air-Sea-Ice-Lab Project. M. O. acknowledges B. GiuliNico for interesting discussions. Buoy data are publicly available online (https://doi. org/10.26179/5cc934992f065).

\section{References}

Ackley, S. F., Xie, H., \& Tichenor, E. A. (2015). Ocean heat flux under antarctic sea ice in the Bellingshausen and Amundsen Seas: Two case studies. Annals of Glaciology, 56(69), 200,210. https://doi.org/10.3189/2015AoG69A890

Alberello, A., Onorato, M., Bennetts, L., Vichi, M., Eayrs, C., MacHutchon, K., \& Toffoli, A. (2019). Pancake ice floe size distribution during the winter expansion of the Antarctic marginal ice zone. The Cryosphere, 13(1), 41-48. https://doi.org/10.5194/tc-13-41-2019

Alberello, A., Onorato, M., Frascoli, F., \& Toffoli, A. (2019). Observation of turbulence and intermittency in wave-induced oscillatory flows. Wave Motion, 84, 81-89. https://doi.org/10.1016/j.wavemoti.2018.10.003

Andersen, S.-N., Tonboe, R., Kern, S., \& Schyberg, H. (2006). Improved retrieval of sea ice total concentration from spaceborne passive microwave observations using numerical weather prediction model fields: An intercomparison of nine algorithms. Remote Sensing of Environment, 104(4), 374-392. https://doi.org/10.1016/j.rse.2006.05.013

Arndt, J. E., Schenke, H. W., Jakobsson, M., Nitsche, F. O., Buys, G., Goleby, B., et al. (2013). The International Bathymetric Chart of the Southern Ocean (IBCSO) Version 1.0-A new bathymetric compilation covering circum-Antarctic waters. Geophysical Research Letters, 40, 3111-3117. https://doi.org/10.1002/grl.50413

Barthélemy, A., Goosse, H., Fichefet, T., \& Lecomte, O. (2018). On the sensitivity of Antarctic sea ice model biases to atmospheric forcing uncertainties. Climate Dynamics, 51(4), 1585-1603. https://doi.org/10.1007/s00382-017-3972-7

Beitsch, A., Kaleschke, L., \& Kern, S. (2014). Investigating high-resolution AMSR2 sea ice concentrations during the February 2013 fracture event in the Beaufort Sea. Remote Sensing, 6(5), 3841-3856. https://doi.org/10.3390/rs6053841

Beitsch, A., Kern, S., \& Kaleschke, L. (2015). Comparison of SSM/I and AMSR-E sea ice concentrations with aspect ship observations around Antarctica. IEEE Transactions on Geoscience and Remote Sensing, 53(4), 1985-1996. https://doi.org/10.1109/TGRS.2014.2351497

Bennetts, L. G., O'Farrell, S., \& Uotila, P. (2017). Impacts of ocean-wave-induced breakup of Antarctic sea ice via thermodynamics in a stand-alone version of the CICE sea-ice model. The Cryosphere, 11(3), 1035-1040. https://doi.org/10.5194/tc-11-1035-2017

Bennetts, L. G., \& Williams, T. D. (2015). Water wave transmission by an array of floating discs. Proceedings of the Royal Society A: Mathematical, Physical and Engineering Sciences, 471(2173), 20140698. https://doi.org/10.1098/rspa.2014.0698

Boutin, G., Lique, C., Ardhuin, F., Rousset, C., Talandier, C., Accensi, M., \& Girard-Ardhuin, F. (2019). Toward a coupled model to investigate wave-sea ice interactions in the Arctic marginal ice zone. The Cryosphere Discussions, 2019, 1-39. https://doi.org/10.5194/ tc-2019-92

Castellani, G., Losch, M., Ungermann, M., \& Gerdes, R. (2018). Sea-ice drag as a function of deformation and ice cover: Effects on simulated sea ice and ocean circulation in the Arctic. Ocean Modelling, 128, 48-66. https://doi.org/10.1016/j.ocemod.2018.06.002

Connolley, W. M., Gregory, J. M., Hunke, E., \& McLaren, A. J. (2004). On the consistent scaling of terms in the sea-ice dynamics equation. Journal of Physical Oceanography, 34(7), 1776-1780. https://doi.org/10.1175/1520-0485(2004)034<1776:OTCSOT>2.0.CO;2

Coon, M. D., Maykut, G. A., Pritchard, R. S., Rothrock, D. A., \& Thorndike, A. S. (1974). Modeling the pack ice as an elastic-plastic material. AIDJEX Bulletin, 24, 1-105.

Copernicus Climate Change Service (C3S) (2017). ERA5: Fifth generation of ECMWF atmospheric reanalyses of the global climate. Reading, UK: Copernicus Climate Change Service Climate Data Store (CDS). Retrieved from https://cds.climate.copernicus.eu/cdsapp\#!/home

Cushman-Roisin, B., \& Beckers, J.-M. (2011). Introduction to geophysical fluid dynamics: Physical and numerical aspects (Vol. 101). Amsterdam, Netherlands: Academic Press.

Dai, H. J., McWilliams, J. C., \& Liang, J. H. (2019). Wave-driven mesoscale currents in a marginal ice zone. Ocean Modelling, $134,1-17$. https://doi.org/10.1016/j.ocemod.2018.11.006

Dai, M., Shen, H. H., Hopkins, M. A., \& Ackley, S. F. (2004). Wave rafting and the equilibrium pancake ice cover thickness. Journal of Geophysical Research, 109, C07023. https://doi.org/10.1029/2003JC002192

de Jong, E., Vichi, M., Mehlmann, C. B., Eayrs, C., De Kock, W., Moldenhauer, M., \& Audh, R. R. (2018). Sea Ice conditions within the Antarctic Marginal Ice Zone in Winter 2017, onboard the SA Agulhas II [data set]. PANGAEA https://doi.org/10.1594/PANGAEA. 885211

Doble, M. J. (2009). Simulating pancake and frazil ice growth in the Weddell Sea: A process model from freezing to consolidation. Journal of Geophysical Research, 114, C09003. https://doi.org/10.1029/2008JC004935

Doble, M. J., \& Bidlot, J. R. (2013). Wave buoy measurements at the Antarctic sea ice edge compared with an enhanced ECMWF WAM: Progress towards global waves-in-ice modelling. Ocean Modelling, 70, 166-173. Ocean Surface Waves https://doi.org/10.1016/j.ocemod. 2013.05.012 
Doble, M. J., Coon, M. D., \& Wadhams, P. (2003). Pancake ice formation in the Weddell Sea. Journal of Geophysical Research, 108(C7), 3209. https://doi.org/10.1029/2002JC001373

Doble, M. J., \& Wadhams, P. (2006). Dynamical contrasts between pancake and pack ice, investigated with a drifting buoy array. Journal of Geophysical Research, 111, C11S24. https://doi.org/10.1029/2005JC003320

Feltham, D. L. (2005). Granular flow in the marginal ice zone. Philosophical Transactions of the Royal Society A: Mathematical, Physical and Engineering Sciences, 363(1832), 1677-1700. https://doi.org/10.1098/rsta.2005.1601

Feltham, D. L. (2008). Sea ice rheology. Annual Review of Fluid Mechanics, 40(1), 91-112. https://doi.org/10.1146/annurev.fluid.40.111406. 102151

Gimbert, F., Marsan, D., Weiss, J., Jourdain, N. C., \& Barnier, B. (2012). Sea ice inertial oscillations in the Arctic Basin. The Cryosphere, 6(5), 1187-1201. https://doi.org/10.5194/tc-6-1187-2012

Grotmaack, R., \& Meylan, M. H. (2006). Wave forcing of small floating bodies. Journal of Waterway, Port, Coastal, and Ocean Engineering, 132(3), 192-198. https://doi.org/10.1061/(ASCE)0733-950X(2006)132:3(192)

Heil, P., \& Allison, I. (1999). The pattern and variability of Antarctic sea-ice drift in the Indian Ocean and western Pacific sectors. Journal of Geophysical Research, 104(C7), 15,789-15,802. https://doi.org/10.1029/1999JC900076

Heil, P., \& Hibler, W. D. (2002). Modeling the high-frequency component of Arctic sea ice drift and deformation. Journal of Physical Oceanography, 32(11), 3039-3057. https://doi.org/10.1175/1520-0485(2002)032<3039:MTHFCO>2.0.CO;2

Herman, A. (2012). Influence of ice concentration and floe-size distribution on cluster formation in sea-ice floes. Central European Journal of Physics, 10(3), 715-722. https://doi.org/10.2478/s11534-012-0071-6

Hobbs, W. R., Bindoff, N. L., \& Raphael, M. N. (2015). New perspectives on observed and simulated Antarctic sea ice extent trends using optimal fingerprinting techniques. Journal of Climate, 28(4), 1543-1560. https://doi.org/10.1016/j.gloplacha.2016.06.008

Hobbs, W. R., Massom, R., Stammerjohn, S., Reid, P., Williams, G., \& Meier, W. (2016). A review of recent changes in Southern Ocean sea ice, their drivers and forcings. Global and Planetary Change, 143, 228-250. https://doi.org/10.1175/JCLI-D-14-00367.1

Hopkins, M. A., \& Shen, H. H. (2001). Simulation of pancake-ice dynamics in a wave field. Annals of Glaciology, 33, 355-360. https://doi. org/10.3189/172756401781818527

Howard, S. L., Hyatt, J., \& Padman, L. (2004). Mixing in the pycnocline over the western Antarctic Peninsula shelf during Southern Ocean GLOBEC. Deep Sea Research Part II: Topical Studies in Oceanography, 51(17), 1965-1979. Integrated Ecosystem Studies of Western Antarctic Peninsula Continental Shelf Waters and Related Southern Ocean Regions https://doi.org/10.1016/j.dsr2.2004.08.002

Hunke, E. C., Lipscomb, W. H., \& Turner, A. K. (2010). Sea-ice models for climate study: Retrospective and new directions. Journal of Glaciology, 56(200), 11621172. https://doi.org/10.3189/002214311796406095

Johannessen, O. M., Johannessen, J. A., Morison, J., Farrelly, B. A., \& Svendsen, E. A. S. (1983). Oceanographic conditions in the marginal ice zone north of Svalbard in early fall 1979 with an emphasis on mesoscale processes. Journal of Geophysical Research, 88(C5), 2755-2769. https://doi.org/10.1029/JC088iC05p02755

Kohout, A. L., Penrose, B., Penrose, S., \& Williams, MichaelJ. M. (2015). A device for measuring wave-induced motion of ice floes in the Antarctic marginal ice zone. Annals of Glaciology, 56(69), 415,424. https://doi.org/10.3189/2015AoG69A600

Kwok, R., Pang, S. S., \& Kacimi, S. (2017). Sea ice drift in the Southern Ocean: Regional patterns, variability, and trends. Elementa: Science of the Anthropocene, 5, 32. https://doi.org/10.1525/elementa.226

Lavergne, T., Eastwood, S., Teffah, Z., Schyberg, H., \& Breivik, L.-A. (2010). Sea ice motion from low-resolution satellite sensors: An alternative method and its validation in the Arctic. Journal of Geophysical Research, 115, C10032. https://doi.org/10.1029/2009JC005958 Leppäranta, M. (2011). The drift of sea ice. Chirchester, UK: Springer Science \& Business Media.

Lindsay, R. W. (2002). Ice deformation near SHEBA. Journal of Geophysical Research, 107(C10), 8042. https://doi.org/10.1029/ 2000JC000445

Lund, B., Graber, H. C., Persson, P. O. G., Smith, M., Doble, M., Thomson, J., \& Wadhams, P. (2018). Arctic sea ice drift measured by shipboard marine radar. Journal of Geophysical Research: Oceans, 123, 4298-4321. https://doi.org/10.1029/2018JC013769

Mack, S., Padman, L., \& Klinck, J. (2013). Extracting tidal variability of sea ice concentration from AMSR-E passive microwave single-swath data: A case study of the Ross Sea. Geophysical Research Letters, 40, 547-552. https://doi.org/10.1002/grl.50128

Manucharyan, G. E., \& Thompson, A. F. (2017). Submesoscale sea ice-ocean interactions in marginal ice zones. Journal of Geophysical Research: Oceans, 122, 9455-9475. https://doi.org/10.1002/2017JC012895

Martinson, D. G., \& Wamser, C. (1990). Ice drift and momentum exchange in winter Antarctic pack ice. Journal of Geophysical Research, 95(C2), 1741-1755. https://doi.org/10.1029/JC095iC02p01741

Masson, D. (1991). Wave-induced drift force in the marginal ice zone. Journal of Physical Oceanography, 21, 3-10. https://doi.org/10.1175/ 1520-0485(1991)021<0003:WIDFIT>2.0.CO;2

Matear, R. J., O'Kane, T. J., Risbey, J. S., \& Chamberlain, M. (2015). Sources of heterogeneous variability and trends in Antarctic sea-ice. Nature communications, 6, 8656 .

McPhee, M. G. (1982). Sea ice drag laws and simple boundary layer concepts, including application to rapid melting (Tech. Rep.). Cold Regions Research and Engineering Lab Hanover NH.

McPhee, M. G., Maykut, G. A., \& Morison, J. H. (1987). Dynamics and thermodynamics of the ice/upper ocean system in the marginal ice zone of the Greenland Sea. Journal of Geophysical Research, 92(C7), 7017-7031. https://doi.org/10.1029/JC092iC07p07017

Meyer, A., Sundfjord, A., Fer, I., Provost, C., Villacieros Robineau, N., Koenig, Z., et al. (2017). Winter to summer oceanographic observations in the Arctic Ocean north of Svalbard. Journal of Geophysical Research, 122, 6218-6237. https://doi.org/10.1002/2016JC012391

Nakayama, Y., Ohshima, K. I., \& Fukamachi, Y. (2012). Enhancement of sea ice drift due to the dynamical interaction between sea ice and a coastal ocean. Journal of Physical Oceanography, 42(1), 179-192. https://doi.org/10.1175/JPO-D-11-018.1

Nansen, F. (1902). Oceanography of the North Polar Basin. Scientific Results, 3(9), 1-427.

Notz, D. (2012). Challenges in simulating sea ice in Earth System Models. Wiley Interdisciplinary Reviews: Climate Change, 3(6), 509-526. Overland, J. E. (1985). Atmospheric boundary layer structure and drag coefficients over sea ice. Journal of Geophysical Research, 90(C5), 9029-9049. https://doi.org/10.1029/JC090iC05p09029

Padman, L., Siegfried, M. R., \& Fricker, H. A. (2018). Ocean tide influences on the Antarctic and Greenland ice sheets. Reviews of Geophysics, 56, 142-184. https://doi.org/10.1002/2016RG000546

Pedersen, L. T., \& Coon, M. D. (2004). A sea ice model for the marginal ice zone with an application to the Greenland Sea. Journal of Geophysical Research, 109(C3), C03008. https://doi.org/10.1029/2003JC001827

Peterson, A. K., Fer, I., McPhee, M. G., \& Randelhoff, A. (2017). Turbulent heat and momentum fluxes in the upper ocean under Arctic sea ice. Journal of Geophysical Research: Oceans, 122, 1439-1456. https://doi.org/10.1002/2016JC012283

Rampal, P., Dansereau, V., Olason, E., Bouillon, S., Williams, T., Korosov, A., \& Samaké, A. (2019). On the multi-fractal scaling properties of sea ice deformation. The Cryosphere, 13(9), 2457-2474. https://doi.org/10.5194/tc-13-2457-2019 
Roach, L. A., Dean, S. M., \& Renwick, J. A. (2018). Consistent biases in Antarctic sea ice concentration simulated by climate models. The Cryosphere, 12(1), 365-383. https://doi.org/10.5194/tc-12-365-2018

Roach, L. A., Horvat, C., Dean, S. M., \& Bitz, C. M. (2018). An emergent sea ice floe size distribution in a global coupled ocean sea ice model. Journal of Geophysical Research: Oceans, 123, 4322-4337. https://doi.org/10.1029/2017JC013692

Roach, L. A., Smith, M., \& Dean, S. (2018). Quantifying growth of pancake sea ice floes using images from drifting buoys. Journal of Geophysical Research: Oceans, 123, 2851-2866. https://doi.org/10.1002/2017JC013693

Schroeter, S., Hobbs, W., \& Bindoff, N. L. (2017). Interactions between Antarctic sea ice and large-scale atmospheric modes in CMIP5 models. The Cryosphere, 11(2), 789-803. https://doi.org/10.5194/tc-11-789-2017

Shackleton, E. H. (1920). South: The story of Shackleton's last expedition, 1914-1917.

Shen, H. H., Ackley, S. F., \& Yuan, Y. (2004). Limiting diameter of pancake ice. Journal of Geophysical Research, 109, C12035. https://doi. org/10.1029/2003JC002123

Shen, H. H., Hibler III, W. D., \& Leppranta, M. (1987). The role of floe collisions in sea ice rheology. Journal of Geophysical Research, 92(C7), 7085-7096. https://doi.org/10.1029/JC092iC07p07085

Smith, M., Stammerjohn, S., Persson, O., Rainville, L., Liu, G., Perrie, W., et al. (2018). Episodic reversal of autumn ice advance caused by release of ocean heat in the Beaufort Sea. Journal of Geophysical Research: Oceans, 123, 3164-3185. https://doi.org/10.1002/2018JC013764

Smith, M., \& Thomson, J. (2019). Ocean surface turbulence in newly formed marginal ice zones. Journal of Geophysical Research: Oceans, 124, 1382-1398. https://doi.org/10.1029/2018JC014405

Squire, V. A. (2020). Ocean wave interactions with sea ice: A reappraisal. Annual Review of Fluid Mechanics, 52(1), 37-60. https://doi.org/ 10.1146/annurev-fluid-010719-060301

Stevens, R. P., \& Heil, P. (2011). The interplay of dynamic and thermodynamic processes in driving the ice-edge location in the Southern Ocean. Annals of Glaciology, 52(57), 2734. https://doi.org/10.3189/172756411795931642

Strong, C., Foster, D., Cherkaev, E., Eisenman, I., \& Golden, K. M. (2017). On the definition of marginal ice zone width. Journal of Atmospheric and Oceanic Technology, 34(7), 1565-1584. https://doi.org/10.1175/JTECH-D-16-0171.1

Sun, S., \& Shen, H. H. (2012). Simulation of pancake ice load on a circular cylinder in a wave and current field. Cold Regions Science and Technology, 78, 31-39. https://doi.org/10.1016/j.coldregions.2012.02.003

Sutherland, P., \& Dumont, D. (2018). Marginal ice zone thickness and extent due to wave radiation stress. Journal of Physical Oceanography, 48(8), 1885-1901. https://doi.org/10.1175/JPO-D-17-0167.1

Thorndike, A. S. (1986). Kinematics of sea ice. In N. Untersteiner (Ed.), The geophysics of sea ice (pp. 489-549). Boston, MA: Springer US. https://doi.org/10.1029/JC087iC08p05845

Thorndike, A. S., \& Colony, R. (1982). Sea ice motion in response to geostrophic winds. Journal of Geophysical Research, 87(C8), 5845-5852. https://doi.org/10.1007/978-1-4899-5352-0_8

Vichi, M., Eayrs, C., Alberello, A., Bekker, A., Bennetts, L., Holland, D., et al. (2019). Effects of an explosive polar cyclone crossing the Antarctic marginal ice zone. Geophysical Research Letters, 46, 5948-5958. https://doi.org/10.1029/2019GL082457

Vihma, T., Launiainen, J., \& Uotila, J. (1996). Weddell Sea ice drift: Kinematics and wind forcing. Journal of Geophysical Research, 101(C8), 18,279-18,296. https://doi.org/10.1029/96JC01441

Vihma, T., Pirazzini, R., Fer, I., Renfrew, I. A., Sedlar, J., Tjernström, M., et al. (2014). Advances in understanding and parameterization of small-scale physical processes in the marine Arctic climate system: A review. Atmospheric Chemistry and Physics, 14(17), 9403-9450.

Wadhams, P. (1986). The seasonal ice zone. In N. Untersteiner (Ed.), The geophysics of sea ice (pp. 825-991). Boston, MA: Springer US.

Wadhams, P., Aulicino, G., Parmiggiani, F., Persson, P. O. G., \& Holt, B. (2018). Pancake ice thickness mapping in the Beaufort sea from wave dispersion observed in SAR imagery. Journal of Geophysical Research: Oceans, 123, 2213-2237. https://doi.org/10.1002/2017JC013003

Wilkinson, J. P., \& Wadhams, P. (2003). A salt flux model for salinity change through ice production in the Greenland Sea, and its relationship to winter convection. Journal of Geophysical Research: Oceans, 108(C5), 3147. https://doi.org/10.1029/2001JC001099

Williams, T. D., Bennetts, L. G., Squire, V. A., Dumont, D., \& Bertino, L. (2013a). Wave-ice interactions in the marginal ice zone. Part 1: Theoretical foundations. Ocean Modelling, 71, 81-91. https://doi.org/10.1016/j.ocemod.2013.05.010

Williams, T. D., Bennetts, L. G., Squire, V. A., Dumont, D., \& Bertino, L. (2013b). Wave-ice interactions in the marginal ice zone. Part 2: Numerical implementation and sensitivity studies along 1D transects of the ocean surface. Ocean Modelling, 71, 92-101. https://doi.org/ 10.1016/j.ocemod.2013.05.011

Williams, T. D., Rampal, P., \& Bouillon, S. (2017). Wave-ice interactions in the neXtSIM sea-ice model. The Cryosphere, 11(5), $2117-2135$.

Yiew, L. J., Bennetts, L. G., Meylan, M. H., Thomas, G. A., \& French, B. J. (2017). Wave-induced collisions of thin floating disks. Physics of Fluids, 29(12), 127,102. https://doi.org/10.5194/tc-11-2117-2017

Zippel, S., \& Thomson, J. (2016). Air-sea interactions in the marginal ice zone. Elementa: Science of the Anthropocene, 4, 000095. https:// doi.org/10.12952/journal.elementa.000095 